\title{
Joint initiation in bedded clastic rocks
}

\author{
David T. McConaughy ${ }^{1}$, Terry Engelder* \\ Department of Geosciences, The Pennsylvania State University, University Park, PA 16802, USA
}

Received 12 November 1999; accepted 20 June 2000

\begin{abstract}
Two general types of sedimentary structures serve as initiation points (IP) for cross-fold joints in siltstone beds of the Ithaca Formation, Appalachian Plateau, New York: planar bed boundaries and geometrically complex features such as bedforms, trace fossils, and softsediment deformation structures. The relative abundance of each IP type varies with the stratigraphic position of the jointed body. When they are mechanically isolated by thicker shales, siltstone bodies have a higher percentage of IP associated with complex features. This association supports the hypothesis that sedimentary structures serve to concentrate stress, thus becoming preferred sites for primary joint initiation. Secondary joint initiation occurs at planar bed boundaries through interaction with pre-existing joints in adjacent siltstone beds that are mechanically coupled to form composite joints. The propagation path of joints passing through planar bed boundaries of composite joints can be traced backward to primary IP at complex sedimentary structures. Modeling suggests that when beds are mechanically coupled, the modest joint-tip stress concentration across a shale layer (e.g., $<3 \times$ for a 1 -cm thick bed) is equivalent to the stress concentration in the vicinity of a bedform. Consequently, in mechanically coupled siltstone beds, sedimentary structures such as bedforms compete with preexisting joint tips in adjacent beds to initiate new joint segments. (C) 2001 Elsevier Science Ltd. All rights reserved.
\end{abstract}

\section{Introduction}

A number of problems remain in defining the mechanical conditions under which joints initiate in clastic rocks. One problem is that an unreasonably large crackdriving stress is necessary to trigger and then sustain joint propagation from the pervasive and open but very small in situ flaws (i.e., grain-boundary cracks and pores) in clastic rocks. A larger structure is required to magnify the remote stress and, thereby, initiate crack propagation from these open flaws that are otherwise too small for crack growth under geologically reasonable crack-driving stresses. We know that larger structures are required from outcrops on the Appalachian Plateau, New York, where inhomogeneities such as concretions, fossil fragments, ripples and flute casts are the loci of many initiation points (IP) (Bahat and Engelder, 1984). Their clear association with joint initiation is ample evidence that sedimentary structures act to magnify the remote stress at the onset of joint propagation.

Our field study of joints in bedded clastic rocks of the Upper Devonian Genesee Group, Finger Lakes District, New York, focuses on the role of sedimentary structures

\footnotetext{
* Corresponding author.

E-mail address: engelder@geosc.psu.edu (T. Engelder).

${ }^{1}$ Present address: Shell Offshore Inc, New Orleans, LA 70161, USA.
}

in controlling the initiation of joints in beds of a coarser lithology, siltstones in a turbidite sequence. Here, two distinct types of structures concentrate stress in siltstone beds: primary sedimentary structures and pre-existing joints. When siltstone beds are mechanically isolated by thick shale layers stress concentrated by sedimentary structures has a prominent role in joint initiation. When beds are separated by less shale, eliminating mechanical isolation, existing joint tips create stress concentrations that trigger joint propagation in vertically adjacent beds, forming composite joints. In the latter case, sedimentary structures such as bedforms compete with pre-existing joint tips in adjacent beds to initiate new joint segments. We will document the nature of this competition and show how it differs from joint initiation in mechanically isolated beds.

Still, the question remains as to how sedimentary structures magnify the remote stress. One possibility is that differences between the elastic response of siltstone and shale may generate stress concentrations at sedimentary structures, since bedforms are not open cavities that act as large flaws in the traditional sense of linear elastic fracture mechanics. Using models constrained by the shape and size of structures plus data about the locations of joint initiation points, we investigate the mechanical conditions leading to the stress concentration assuming elastic behavior. 


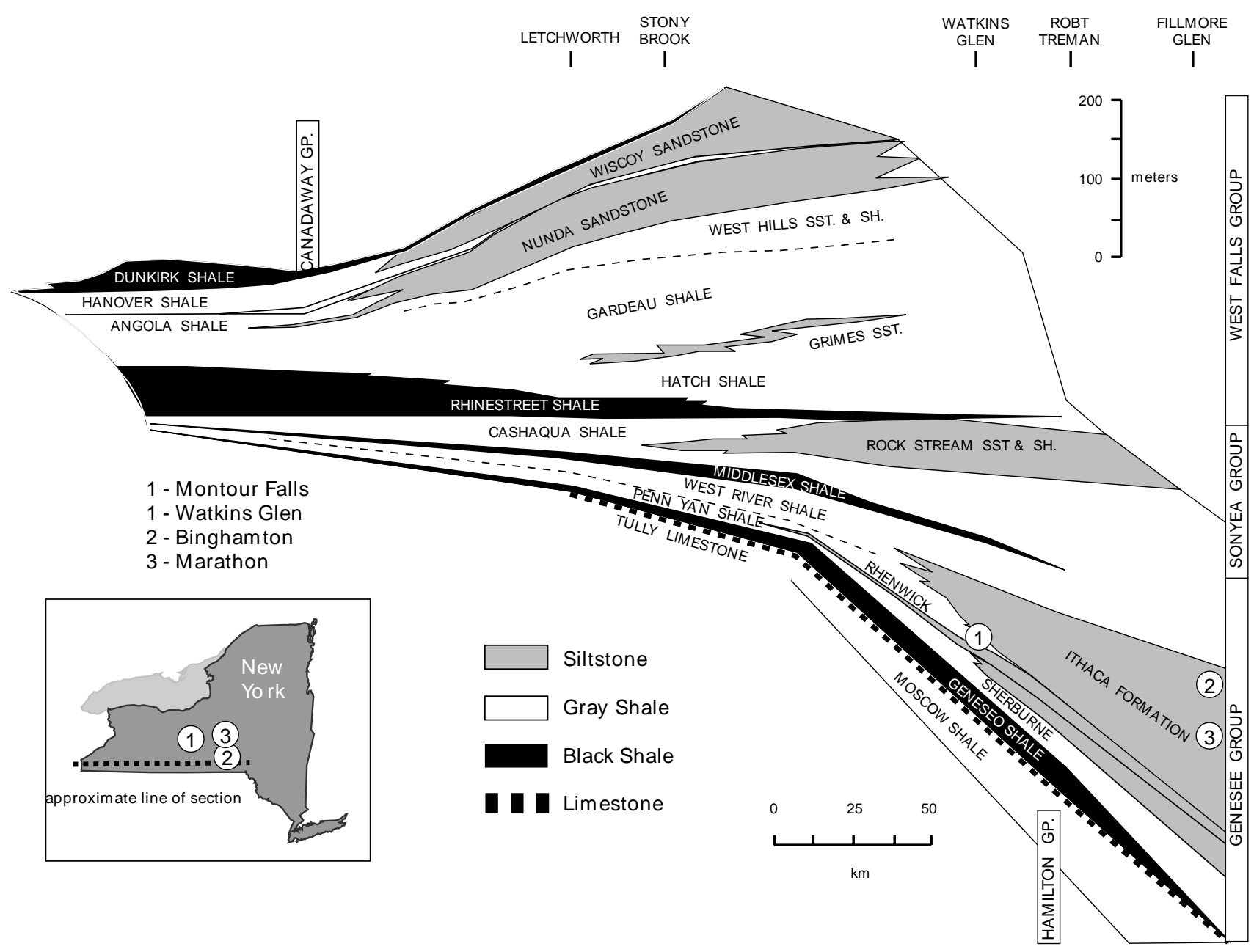

Fig. 1. East-west cross-section through the Devonian Catskill Delta of New York extending from Binghamton, NY, to Erie, PA. Sample localities shown in both cross-section and map view (adapted from Kirchgasser and House, 1981).

\section{Background}

The Ithaca Formation of the Genesee Group is a wedge of siltstone, silty shale, and mudrock that thickens eastward, as part of the Devonian Catskill delta complex in New York (Fig. 1). Siltstone beds range in thickness from thin laminae to several meters, and have sharp erosional bases that exhibit sole markings, current ripples, and small-scale current scours. In contrast to the abrupt change in grain size at the erosional bases, the tops of the beds are less distinct, grading back into shaly intervals.

In the vicinity of Watkins Glen, New York, the Ithaca Formation consists of a sequence of turbidite beds deposited on the basin slope in water depths of about 200 meters (Lundegard et al., 1985). The slow continuous deposition of mud was punctuated by density flows of silt-sized material. These deposits are characterized by laterally continuous beds of siltstone and shale of relatively constant thickness, and mark the distal portions of the prograding Late Devonian Catskill delta complex.

Further to the east, near Marathon and Binghamton, New
York, the turbidite flows were more proximal to the sediment source. Higher depositional rates and steeper slopes caused gravitational instabilities in the sediment column, resulting in soft-sediment deformation. Individual siltstone beds tend to be lenticular, and contain features such as ball and pillow structures, wavy bedding, and storm deposits of shell hash. An increased incidence of vertical burrowing compared to more distal portions of the basin indicates the elevated oxygen content in the water column (Lundegard et al., 1985).

\subsection{Development of cross-fold joints}

The siltstones of the Ithaca Formation are cut by regional vertical joint sets, with the dominant sets oriented roughly perpendicular to the strike of the Alleghanian folds. The strike of these "cross-fold" joint sets varies regionally, from 330-345 near Watkins Glen to 350-020 in the eastern portions of the study area (Younes and Engelder, 1999). The cross-fold joints are well developed in most stratigraphic units in the Appalachian Basin, and their development is 


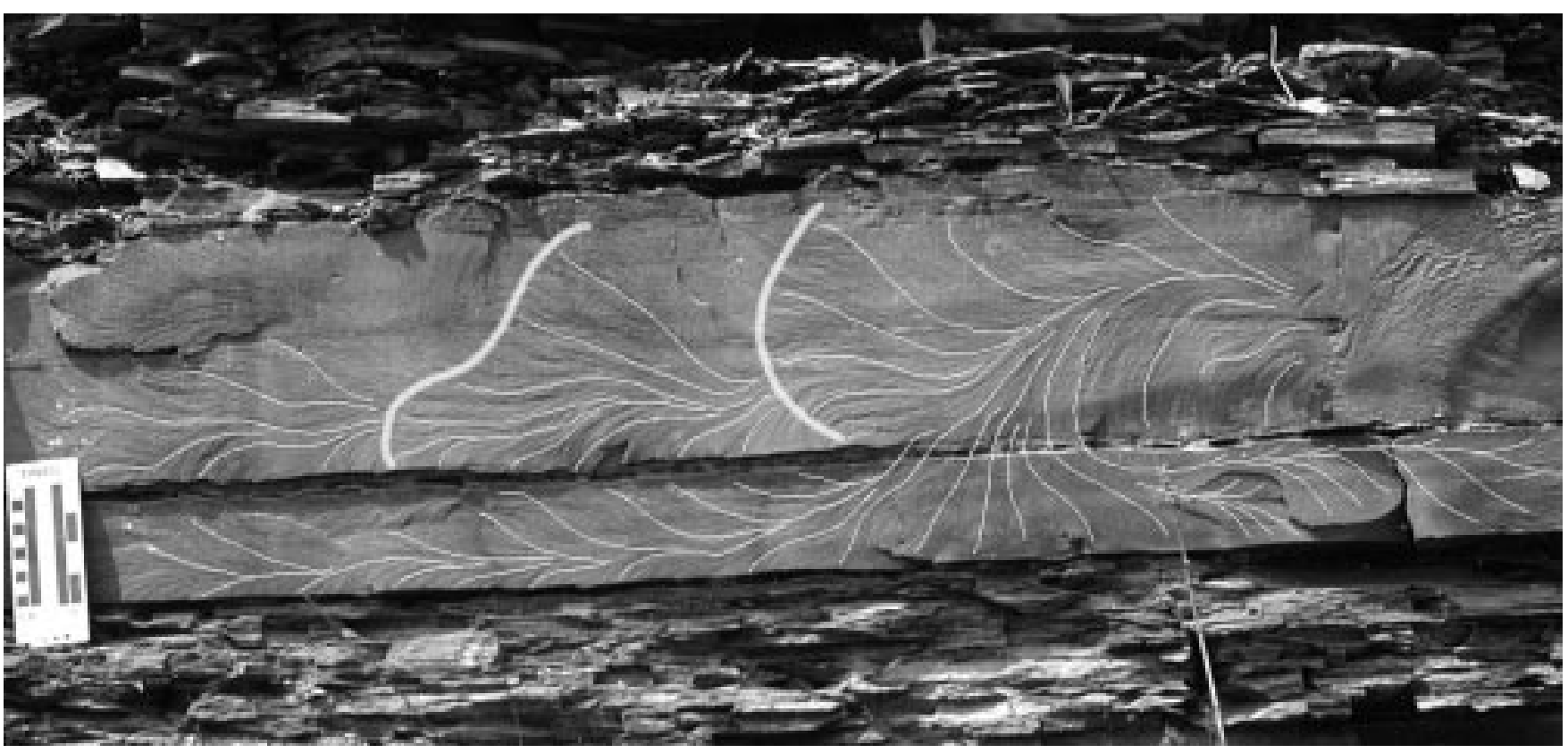

Fig. 2. Composite joint with an interpretation of joint propagation through Beds A (upper) and B (lower) from the Montour Falls outcrop. Fine white lines trace the plumose morphology, fanning out in the direction of joint propagation. The joint in Bed A was initiated out of the field of view on the right. Heavier lines mark arrest lines in Bed A as indicated by abrupt changes in the relief of the hackle. The plumose morphology is interpreted to show that the joint crossed the shale interlayer along a $10-\mathrm{cm}$ wide front, then propagated laterally as individual joints in the two siltstone beds. The joint in the lower bed is interpreted to have propagated to the left before the joint in the upper bed which halted, at least momentarily, at the first arrest line. Hence, this joint in the lower bed would have caused the offset of the two joint planes and the downward shift in the axis of the upper plume when propagation of the upper joint continued to the left.

consistent with kinematics of the late Paleozoic Alleghanian deformation (Nickelsen and Hough, 1967; Engelder and Geiser, 1980; Bahat and Engelder, 1984; Evans, 1994; Zhao and Jacobi, 1997).

\subsection{Joint surface morphology}

Cross-fold joints exhibit well-developed plumose surface morphology in siltstone beds of the Ithaca Formation (Fig. 2 ). The plumes consist of low-relief ridges and hollows that form a delicate feathery pattern along a joint surface and record joint propagation during growth. Three phases of joint growth, initiation, propagation, and arrest can be identified by inspection of plumose morphology (Hodgson, 1961; Bankwitz, 1965; Kulander et al., 1979; Bahat and Engelder, 1984; Kulander and Dean, 1985). The low-relief ridges, or hackle marks, are parallel to the direction of joint propagation, radiating out from the axis of the plume. The relief of hackle marks commonly increases as the joint propagates, becoming coarsest near arrest lines and at bed boundaries. The hackle marks converge on a location from which the joint originated at the initiation point, IP.

\subsection{Mechanical coupling of beds}

A composite joint consists of joints in several closelyspaced siltstone beds where the joints have propagated vertically in nearly the same plane from one bed to the next (Fig. 2 ). The propagation takes place as a consequence of the projection of the crack-tip stress field across thin shale interlayers (Helgeson and Aydin, 1991). Growth of a composite joint is possible because adjacent beds are mechanically coupled. Thicker shale layers act to mechanically isolate individual beds so that joint growth in the isolated bed is not influenced by the crack-tip stress field of a joint in another bed. On the Appalachian Plateau, mechanical isolation is commonly achieved with shale interlayers less than $40 \mathrm{~cm}$ thick (Fig. 3). Pairs of beds can be mechanically isolated from adjacent beds by interlayered shale and yet, the pair can be coupled if the shale interlayer is relatively thin. Mechanical coupling is best achieved when shale interlayers are less than $1 \mathrm{~cm}$ thick.

\section{Sample localities}

Initiation point data were collected at two outcrops separated by about $2 \mathrm{~km}$ in the vicinity of Watkins Glen (Fig. 1). The first is located along Highway 14 between Watkins Glen and Montour Falls, the Montour Falls outcrop, and the second is located on Highway 414 just south of its intersection with Highway 14, the Watkins Glen outcrop. At the Montour Falls outcrop a cross-fold $\left(335^{\circ}\right)$ joint set strikes parallel to the road, providing exposure of individual joint surfaces of up to 10 meters in length. A sequence of four individual siltstone beds crops out along a $500 \mathrm{~m}$ stretch of Highway 14 (Fig. 3). These beds are located within a 3meter thick interval of the Ithaca Formation and range in thickness from 8 to $20 \mathrm{~cm}$. 


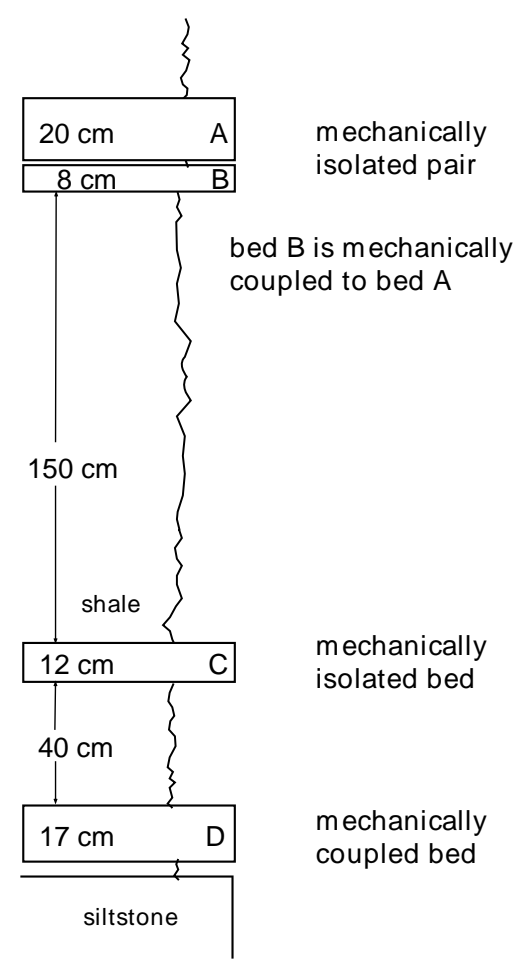

Fig. 3. Schematic cross-section through four siltstone beds of the Ithaca Formation at the Montour Falls outcrop. Beds A and B are those shown in Fig. 2. This cross-section illustrates the distinction between mechanically isolated beds and mechanically coupled beds. Although the joint faces on the right side of the siltstone beds of this schematic cross-section are aligned in a vertical plane, they are not aligned in such a manner in the outcrop.

The Watkins Glen outcrop, $3 \mathrm{~km}$ to the north, exposes a sequence of interbedded shales and siltstones that range between 5 and $20 \mathrm{~cm}$ in thickness and contain the $335^{\circ}$ joint set. Exposure of individual joint surfaces is generally limited to less than a meter in length due to the angle of intersection between the strike of the joints and the trend of the roadcut.

Approximately $60 \mathrm{~km}$ to the east, other outcrops for this study are found on the southbound entrance ramp to I-81 at the town of Marathon, and along Pennsylvania Avenue just south of Binghamton, New York. The rocks of these outcrops are positioned stratigraphically higher than the Montour Falls and Watkins Glen outcrops, near the top of the Ithaca Formation. The interbedded shales and siltstones have undergone significant soft-sediment deformation. Storm deposits' of shell hash, hummocky bedding, and ball-and-pillow structures are evidence of a shallower depositional environment. Joints in the siltstone beds in the vicinity of Marathon and Binghamton strike from $358^{\circ}$ to $020^{\circ}$, whereas the shales carry a joint set striking $075^{\circ}$ (Younes and Engelder, 1999).

\section{Initiation point classification}

Key field observations include the location of the IP with respect to the bed (e.g. base, middle, top), the nature and geometry of the sedimentary feature with which the IP are associated, and the vertical alignment of IP relative to joint tips in mechanically-coupled beds. We distinguish a type of IP associated with complex sedimentary structures from a second type of IP found at planar bed boundaries: there are three categories of irregularly shaped sedimentary structures displaying initiation points. Bedforms, trace fossils, and other less common features grouped into a third category that includes nodules, concretions, fossils, shale laminae, and soft-sediment deformation structures.

\subsection{Sedimentary bedforms}

Bedforms associated with IP are primarily erosional in origin and developed during turbidite deposition of the Ithaca Formation siltstones. Density currents eroded the muddy substrate producing convex features on the bottom of the siltstone beds filled with coarser sediment. Bedforms include groove casts, gutter casts, flute casts, and current ripples. Groove casts are very common elongate features that typically have a convex asymmetrical, U-shaped cross-section, a few centimeters in width (Fig. 4). Much less common are gutter casts that resemble groove casts but are larger, ranging from 8 to $15 \mathrm{~cm}$ in width and 2 to $5 \mathrm{~cm}$ in depth. Cross-sectional profiles of gutter casts show a more bulbous geometry than groove casts (Fig. 5).

Initiation points associated with bedforms are commonly located in one of two positions with respect to the bedform. The asymmetry of the bedforms often results in a sharp angular contact between the cast and the base of the bed on one side. The plume may initiate at a point where the bedform joins the base of the bed, or may be located at a vertical surface along the interface (Figs. 4 and 5). In some instances, the long axis of the bedform intersects the strike of the joint at an oblique angle. The plane of the joint in the immediate vicinity of the initiation point will typically be misaligned with the overall strike of the joint in such cases. The plume in Fig. 4 branches into two fractures, one that propagates to the right into the main part of the bed, and the other develops in the groove cast itself and then propagates to the left back into the bed. A sketch of the vertical plane of the groove cast pictured in Fig. 4 shows that the left branch initially develops orthogonally to the long axis of the groove cast, then twists into the $335^{\circ}$ orientation as it propagates away from the groove cast. This geometry is interpreted to indicate that the groove cast caused a local reorientation of $\sigma_{3}$. Because the tectonic stress field during the Alleghanian orogeny and paleocurrent directions during the Devonian do not correlate, groove casts are rarely in the optimum orientation for the initiation of joint propagation.

Bedforms can be viewed as a random distribution of flaws of differing sizes at the base of the siltstone beds. Often a joint will initiate at one bedform and propagate over several nearby bedforms. Hence, very few bedforms actually act as initiation points. Adjacent joints may have initiated from 

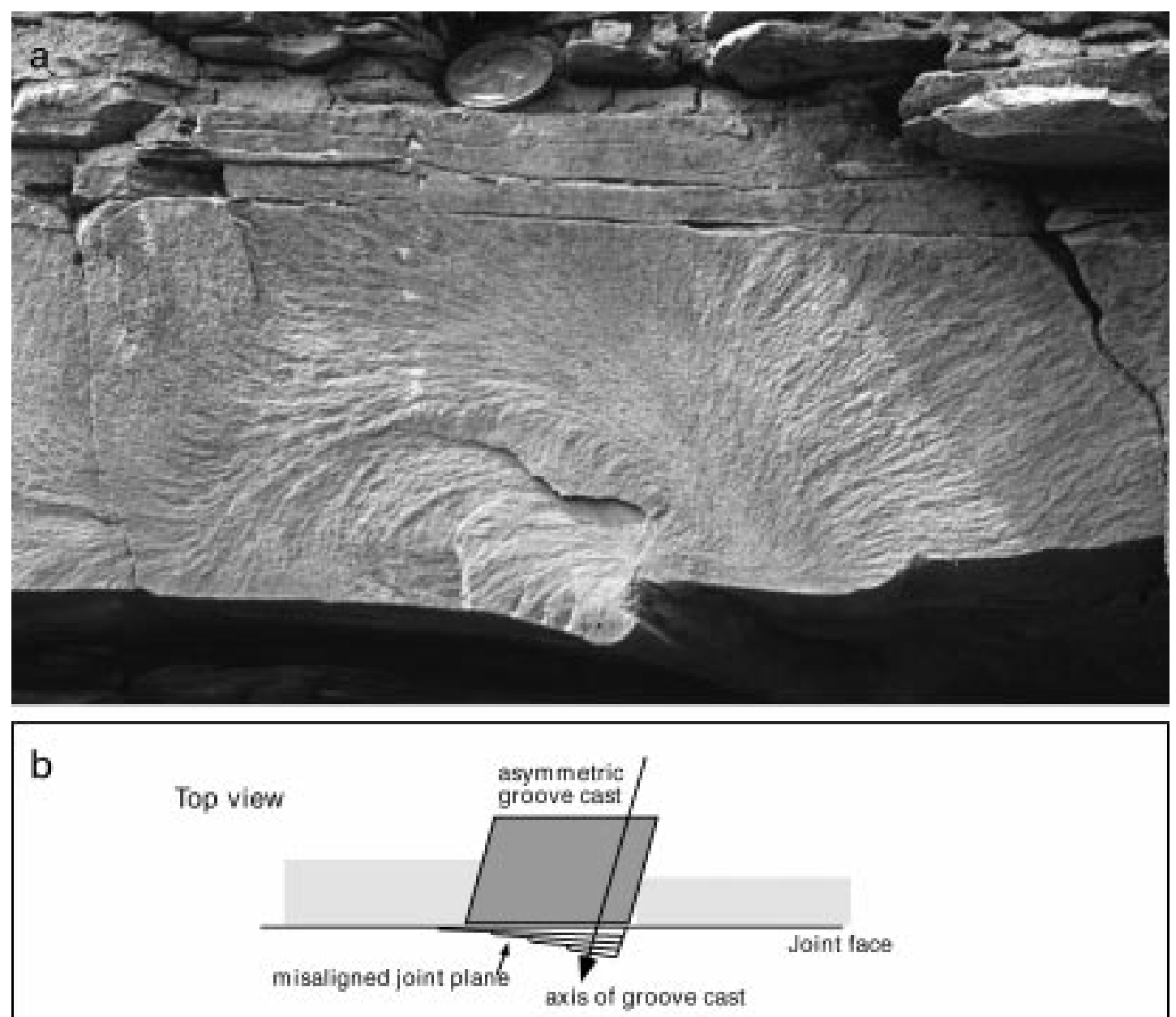

Fig. 4. (a) Initiation points are commonly associated with bedforms such as this groove cast in the Ithaca Formation. The initiation point is located at the corner of the groove cast, where the basal bed boundary changes from horizontal to vertical orientation (U.S. quarter for scale at top of picture). (b) Local reorientation of the stress field near bedforms is indicated by the misalignment of the joint plane at the initiation point with the overall strike of the joint. At the initiation point, the joint is orthogonal to the axis of the groove cast. It twists back into alignment with the regional stress field as it propagates away from the groove cast.

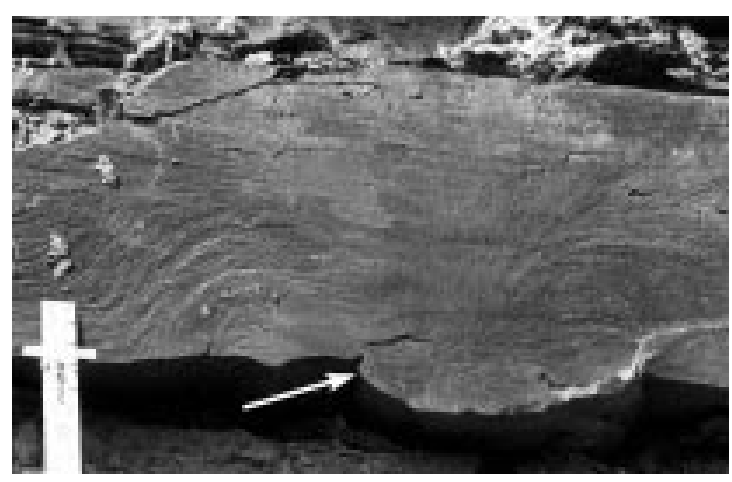

Fig. 5. A joint initiation point coincident with a vertical surface along the cusp of a large (15 cm wide) gutter cast. The underlying shale has eroded back to reveal the linear geometry of the cast, trending E-W, as is typical of density-current-related structures here. The trend is orthogonal to the joint strike, and no misalignment is visible near the initiation point. Scale in centimeters. bedforms separated by a distance of more than an order of magnitude greater than the spacing of the joints.

\subsection{Trace fossils}

A second type of IP is associated with trace fossils, including grazing trails, and horizontal and vertical burrows. These trace fossils are typically circular or elliptical in cross-section, occurring within siltstone beds or at a bed interface (Fig. 6). They may contain sediment of differing size and composition from the surrounding rock. Trace fossils are commonly one or two centimeters in diameter, similar in size to the smaller groove casts. As with bedforms, the IP will generally occur at a point of intersection of the trace fossil with the base of the bed (Fig. 6).

Joint initiation associated with vertical burrows is marked by plumes that originate along the borrow, typically within the middle of a bed (Fig. 7). The line $\mathrm{AA}^{\prime}$ marks the position 


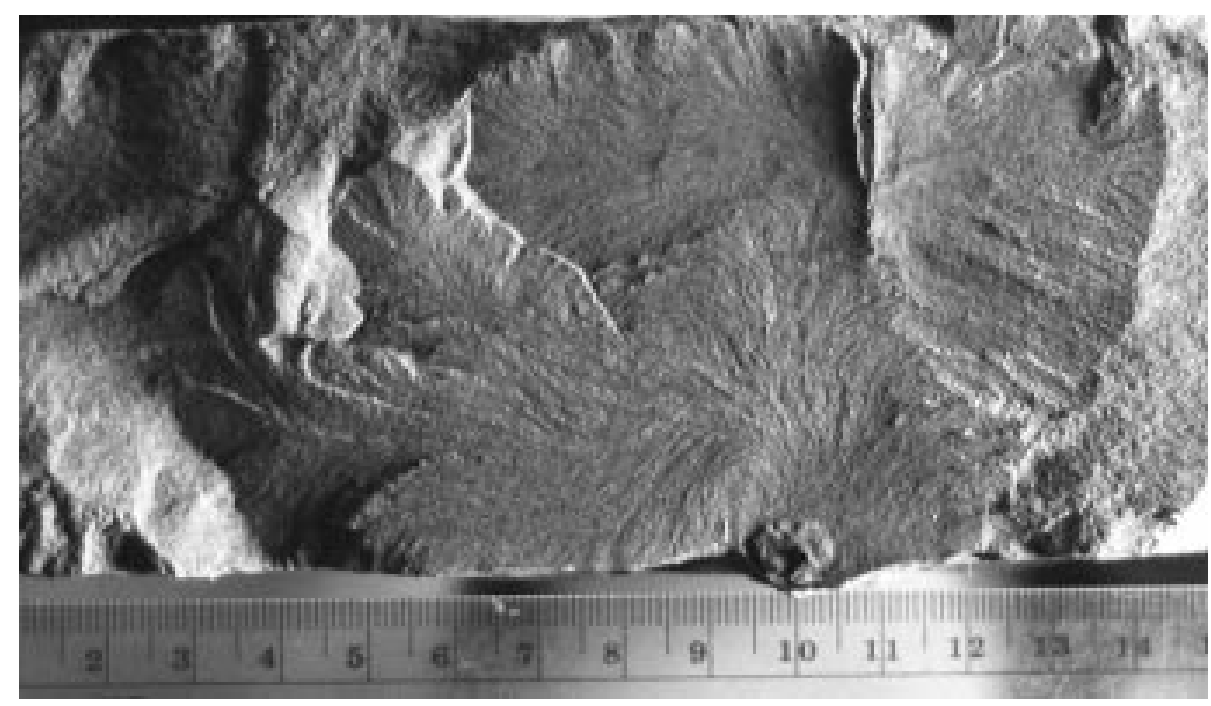

Fig. 6. An example of a trace fossil associated with joint initiation. This horizontal burrow is distinguished from a bedform by its elliptical cross-section, and the clay-sized sediment contained within the burrow. The initiation point is located on the left side of the burrow. Scale in centimeters.

of one of a series of thin sections cut through a burrow in Fig. 7a. A photomicrograph of the thin section shows the interior of the burrow to contain a higher percentage of claysized matrix and platy minerals that are aligned parallel to the burrow walls, than the surrounding siltstone (Fig. 7b). Insoluble residue is present and indicates that pressure solution occurred along the boundaries of the burrow, perhaps reflecting a contrast in competence between the burrow and the surrounding rock. The flattened shape of the burrow in plan view (i.e., Fig. 7b) and the orientation of the pressuresolved surfaces suggests that layer-parallel shortening occurred in a direction parallel to the plane of the joint surfaces (e.g., Engelder, 1979). Joint initiation is localized along the edge of the burrow. The amount of offset between the two joint planes as seen in plan view in Fig. $7 \mathrm{~b}$ varies from 0 to $2 \mathrm{~mm}$ along the axis of the burrow. The joint plane on the right initiated near the base of the bed along the axis on the burrow, and has propagated back toward the burrow at cross section $\mathrm{A}-\mathrm{A}^{\prime}$. The joint surface on the right in Fig. $7 \mathrm{~b}$ curves as it enters the burrow, which results from the interaction of the propagating joint tip with the joint on the left-hand side of the burrow.

\subsection{Other types including soft sedimentary deformation structures}

A variety of less common sedimentary features are grouped together into the 'other' category. Initiation points were observed with ball-and-pillow structures. These structures form early in the consolidation history of the sediments, rather than during deposition, as is the case for the current-related bedforms. They are an indication of high sedimentation rates associated with turbidity currents and storm deposits resulting in loose packing of the sands and silts. These structures consist of discrete packages of sandstone or siltstone surrounded by a matrix of mudstone. The structures are typically ellipsoidal in shape and range in size from tens of centimeters to several meters in diameter (Fig. 8).

The IP of joints in each structure is controlled by local bedform geometry. As observed with many bedforms, the IP are typically located at a region of maximum curvature along the surface of the structure (Fig. 8a). IP tend to occur near vertical surfaces on the perimeter of the siltstone balls. In the more elongate ball-and-pillow structures, the plume tends to propagate along the long axis of the structure (Fig. 8b). At the Marathon outcrop the joints associated with the ball-and-pillow structures strike approximately $\mathrm{N}-\mathrm{S}$, the same joint orientation carried by the coherent siltstone beds. The surrounding shale matrix does not exhibit the same joint orientation.

\subsection{Planar bed boundaries}

Within individual siltstone beds, initiation points may occur along planar surfaces where no bed forms are coincident with the IP. This type of IP is typically a consequence of the mechanical interaction with a joint in an adjacent bed where a relatively thin shale interlayer separated the two beds. When adjacent beds are mechanically coupled to allow the growth of composite joints, joint initiation is driven by the crack-tip stress field of a joint in an adjacent bed (Helgeson and Aydin, 1991). In Fig. 2, tracings of the plumose morphology document the development of a composite joint in two siltstone beds that are separated by a thin shale layer (Beds A and B at Montour Falls; Fig. 3). From its initiation in the upper bed at a flute cast, the joint propagated to the left before arresting. A joint, triggered by the presence of the joint in the upper bed, initiated in the lower bed along a $10-\mathrm{cm}$ wide planar surface and then propagated bilaterally. The crossing point occurs through shale bed about $1 \mathrm{~cm}$ thick. At the crossing point, the joints 

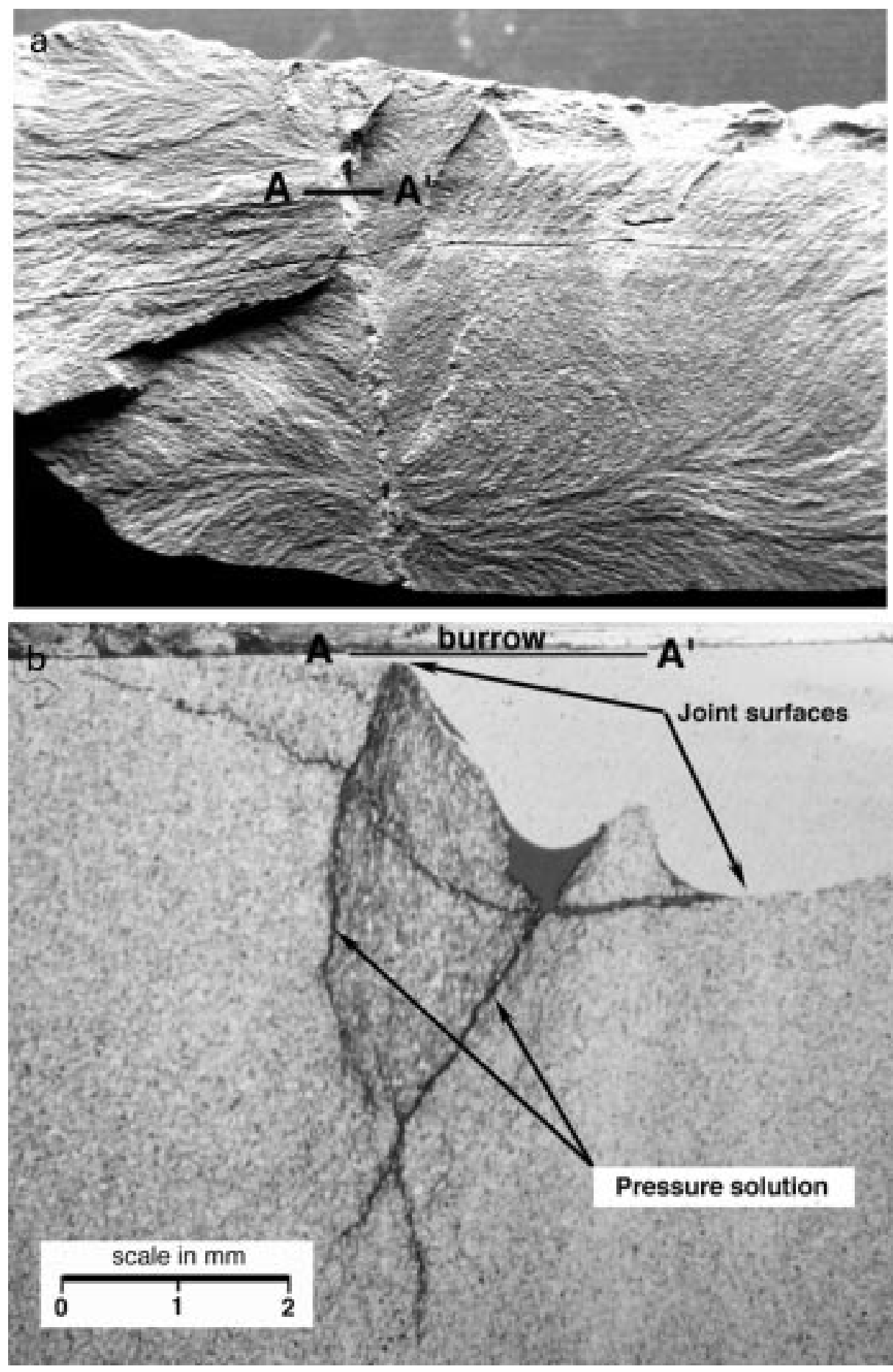

Fig. 7. (a) A 2-mm diameter vertical burrow penetrates through a siltstone bed. The joint initiated at several points along the burrow resulting in a compound joint face. One initiation is near the bottom of the joint and the other is at the cross-section label A-A $\mathrm{A}^{\prime}$. (b) Photomicrograph of a thin section cut normal to the axis of the worm burrow, along cross-section A-A' in Fig. 7a. See text for details.

in these two beds are vertically aligned. Other than at the point of initial rupture in the lower bed, the two joints are not co-planar. Here we say that the joint in the lower bed contains an initiation point at a top planar bed boundary. Technically, we may have argued that lower bed contains no initiation point because the rupture of that bed was a continuation of the growth of a composite joint from upper bed.
In Fig. 2, the position of the propagation axis in the upper bed is noteworthy. While propagating as an isolated joint, the propagation axis of the joint is centered within the upper bed. After the point where the rupture has passed into the lower bed, the propagation axis in the upper bed dips to the lower portion of the upper bed and then arrests. The rupture continues bilaterally in the lower bed without arrest, thereby 

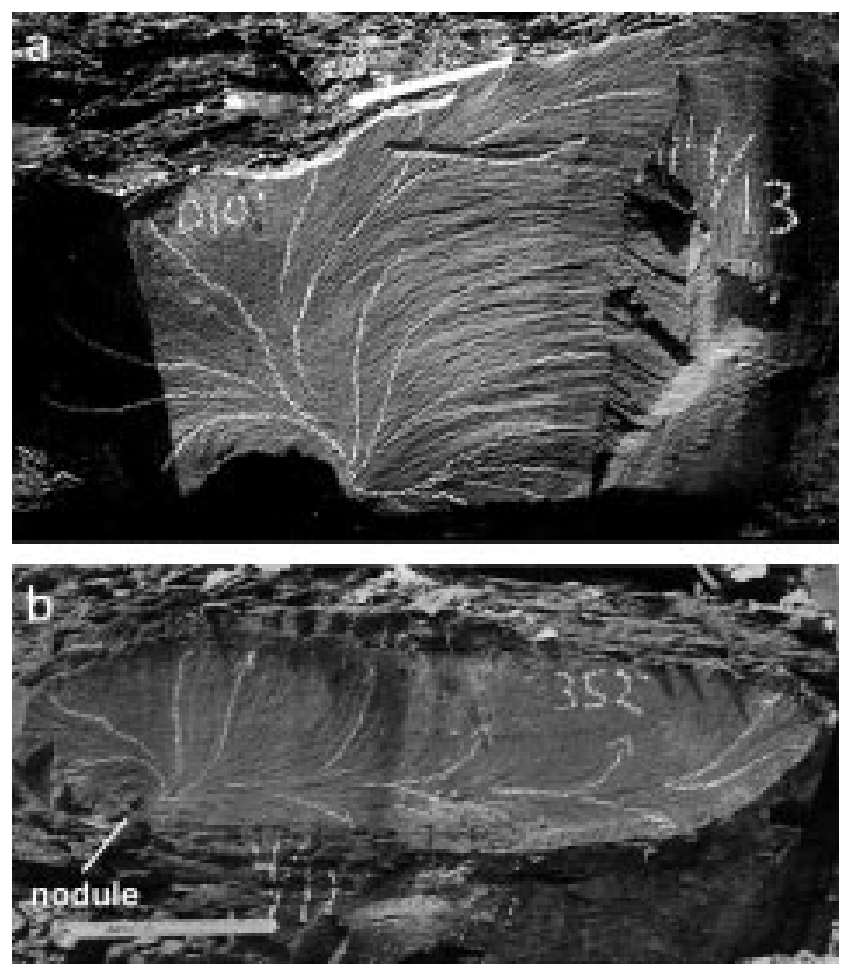

Fig. 8. (a) A large (1 $\mathrm{m}$ diameter) ball-and-pillow structure located at a Binghamton, NY outcrop carries the cross-fold joint orientation $\left(010^{\circ}\right)$. Plumose morphology is highlighted with chalk. The joint initiated at a point where the surface of the siltstone pillow curves sharply, and where the shale-siltstone interface is oriented vertically along the lower boundary. Length of ruler is $15 \mathrm{~cm}$. (b) A siltstone pillow contains a cross-fold joint $\left(352^{\circ}\right)$ whereas the surrounding shale matrix does not. Note the 2 -cm nodule from which the plume initiates, and the fringe cracks in the shale above the siltstone.

allowing joint propagation to the left in the lower bed to reach ahead of joint propagation that halted at the arrest line in the upper bed. Upon reinitiation of propagation in the upper bed, the propagation axis is pulled along the bottom portion of the bed under the influence of a crack-tip stress field created by the joint in the lower bed. This geometry is an example of mechanical coupling between two beds. Note also that in the lower bed, the propagation axis to the right is pulled to the top of the bed by a mechanical coupling with the pre-existing joint in the upper bed.

\subsection{Competition between sedimentary structures and joint tips}

Siltstone beds separated by thin $(<2 \mathrm{~cm})$ shale layers permit mechanical coupling and the growth of joints from one siltstone bed to the next. In this case, sedimentary structures such as bedforms compete with pre-existing joint tips in adjacent beds to locate new joint segments. Beds A and B at Montour Falls illustrate the nature of this competition (Figs. 2 and 9).

Joint propagation initiates at the edge of a small cusp on the base of the upper bed (i.e., Fig. 9, Point 1). This is a primary joint initiation during which the bed ruptures spontaneously without the aid of pre-existing joints. After initiation, the crack front radiates in both directions and grows vertically to fracture Bed A from bottom to top. At an early stage in the growth of the joint in Bed A, joint initiation is triggered in the lower bed through one $\mathrm{cm}$ of shale (Fig. 9, Point 2). The crossing point to Bed B is a secondary joint initiation. The joint in Bed A continues to propagate to Point 3 , where an abrupt decrease in the relief of the hackle along an curving front indicates a change in propagation velocity or arrest of the crack (Kulander et al., 1979). The joint in Bed B also propagates bilaterally with the plume axis located near the top of the bed. As the crack front passes a point aligned with the arrest line in the upper bed, the plume axis shifts downward toward the center of the bed (Fig. 9, Point 4). Point 5 marks a small scallop-shaped crack located near a minor cusp along the base of Bed A. This crack is aligned in the vertical plane with the joint in Bed B but is offset $1 \mathrm{~cm}$ from the main joint in Bed A. The plume of the main joint curves around the small crack (Point 6) indicating that the small crack developed first. The surface morphology provides evidence that the development of joints in the two beds was an interactive process in which the presence of a joint in one bed strongly influenced the subsequent development of the adjacent joint.

The pattern of initiation between the paired beds is consistent along the Montour Falls outcrop. Once a joint initiated in the thinner lower Bed B, plumose morphology indicates a tendency to propagate over longer horizontal distances prior to arresting compared to joints in the thicker Bed A (Figs. 3 and 9). Small scallop-shaped cracks located near minor cusps along the base of Bed A indicate the passing of the crack front in Bed B and subsequent triggering of minor cracks back into the base of Bed A prior to development of the larger joint. Since bedforms are convex features on the base of Bed A, initiation is also coincident with minimum distances between the two beds where very little shale separates the beds. Such back fracturing is characterized by a lack of offset between the two fracture planes, whereas the larger joint planes are typically offset. This behavior, along with the initiation of joints in the lower Bed B associated with first arrival of crack fronts in the upper bed, suggests that joint development in the two beds was a dynamic process. The local crack-tip stress field is particularly important for the subsequent propagation of joints in both beds.

\section{Summary of IP by location and category}

\subsection{Montour Falls outcrop}

Initiation points found in the Montour Falls outcrop are almost exclusively located at the base of the siltstone beds (Fig. 10a). Of the 135 initiation points cataloged, 124 (92\%) were at the bottom of the beds. The erosional base of the 

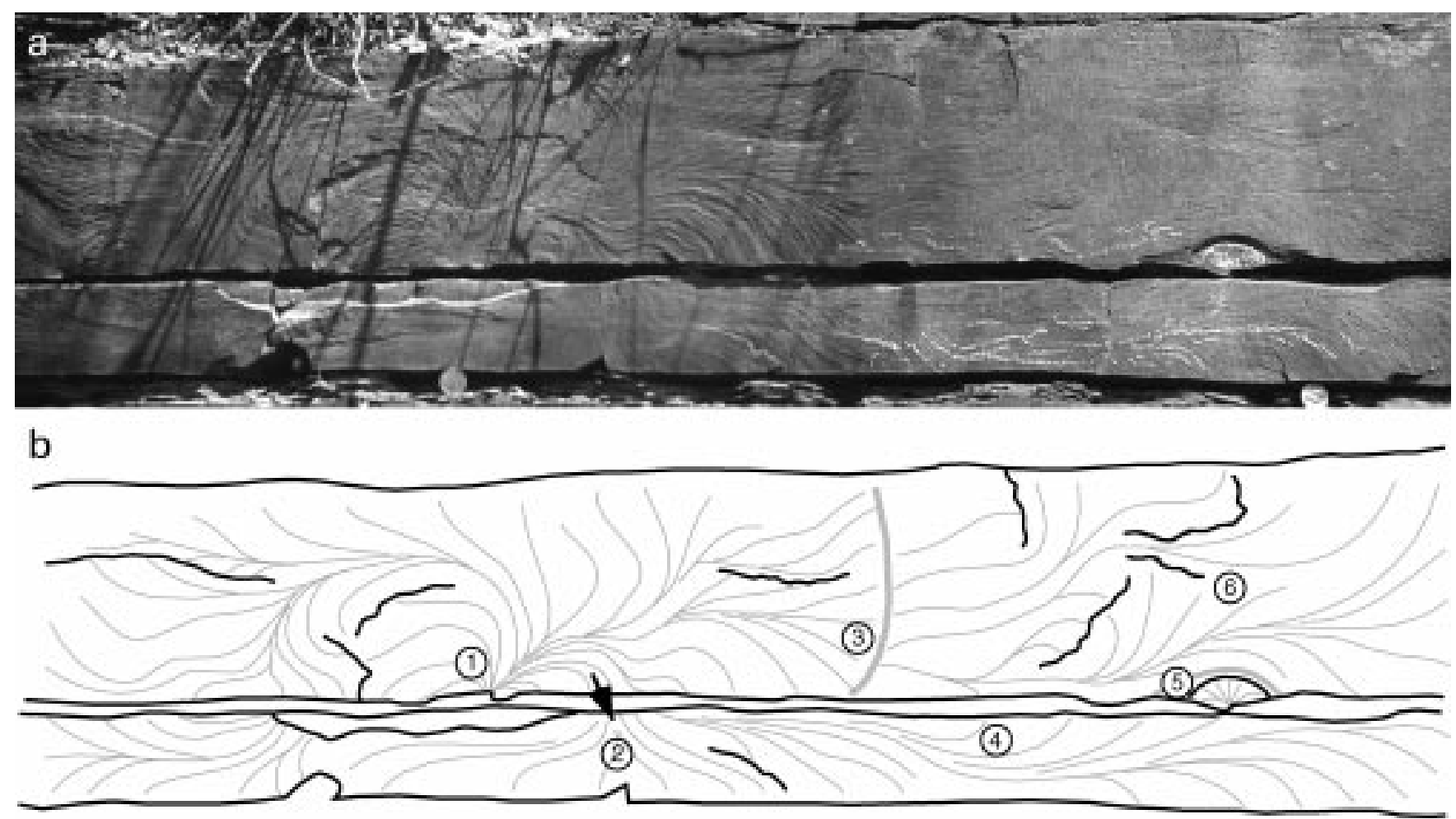

Fig. 9. (a) Plumose morphology on composite joint in Beds A and B, and (b) interpretive tracing. See text for interpretation.

siltstones generates a sharp lithologic contrast with the underlying shale, whereas at the top of the siltstone beds the contact is gradational into the overlying shale. Most initiation points occur along planar bed boundaries or in proximity to bedforms (Fig. 10a). IP associated with trace fossils occur almost exclusively as horizontal burrows at the base of siltstone beds. Occurrences of IP falling into the 'other' category are nearly absent in these beds.

The lateral continuity of these siltstone beds and the parallel orientation of the road cut with respect to the joints permits a comparison of joint initiation between individual beds that differ in thickness and proximity to other siltstone beds (Fig. 11). A pair of adjacent beds, designated Beds A and $\mathrm{B}$, exhibit characteristics of composite joint development on multiple joints (Figs. 3 and 9). The thinner Bed B (8 $\mathrm{cm}$ thick) is separated from the overlying Bed A $(20 \mathrm{~cm}$ thick) by a $1-\mathrm{cm}$ layer of shale. Many IP in Bed B are in plane with the joint in Bed A and occur along its upper boundary where propagation from Bed A to Bed B is in plane. In contrast, IP in Bed A are primarily located at the lower bed boundary, and are associated with either bedforms or planar boundaries, in similar proportions.

Bed C is a mechanically isolated bed, separated from the nearest jointed siltstone by $40 \mathrm{~cm}$ of shale, whereas Bed D is spaced only $3 \mathrm{~cm}$ from an underlying thicker siltstone (mostly covered in this outcrop). A comparison of the two common IP categories found in Beds C and D suggests that the mechanism for initiation may differ between the beds based on their proximity to other beds. All IP in Bed D are located at the base of the bed, and $71 \%$ occurred at planar bed boundaries. In this regard, Bed B and D are similar. The siltstone below Bed D contains $335^{\circ}$ joints that vary along strike in horizontal offset from those in the overlying Bed D from 0 to $4 \mathrm{~cm}$. The bed below Bed D is poorly exposed and could not be studied. Together Bed D and the bed beneath it carry composite joints in which initiation generally occurs first in the lower bed and then in the upper bed. In contrast to Bed D, most IP in Bed C are associated with bedforms (Fig. 11). Since the joints in Bed $C$ are not part of a composite, joints have developed in mechanical isolation from stress perturbations caused by existing joints in other beds. Mechanical isolation is also indicated by the lack of joints in the surrounding shale and the absence of in-plane joints in the adjacent siltstone beds. At the Montour Falls outcrop, 40 $\mathrm{cm}$ of shale is enough to produce mechanical isolation (Fig. 11). Bed C contains some IP at planar boundaries but these IP can not be related to the development of a composite joint.

\subsection{Watkins Glen outcrop}

The outcrop located along Highway 414 in Watkins Glen exposes interbedded siltstones and shales that are positioned higher in the stratigraphic section than those in the Montour Falls outcrop. Overall the sequence is siltier and intercalated shales are only 5 to $20 \mathrm{~cm}$ in thickness. Larger bedforms, gutter casts and flute casts ( $>5 \mathrm{~cm}$ in width) are found in this outcrop, and relatively more bioturbation features are 
a) IP Location - Montour Falls

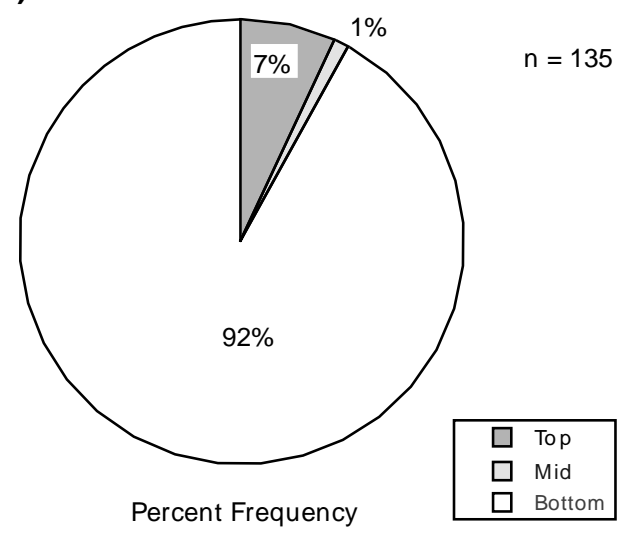

b) IP Location - Watkins Glen

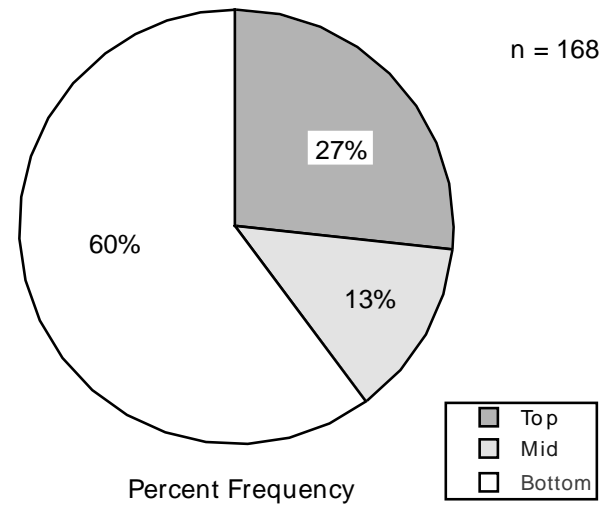

c) IP Location - Proximal outcrops

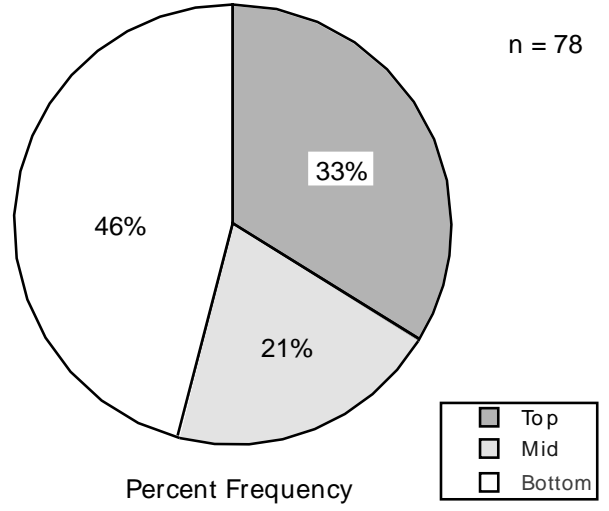

IP Category

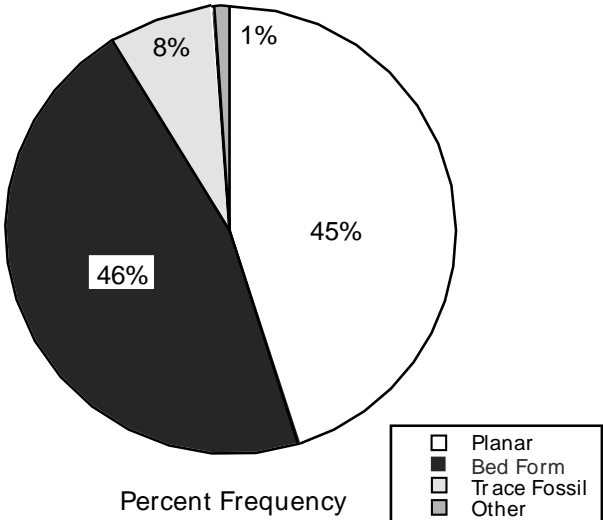

IP Category

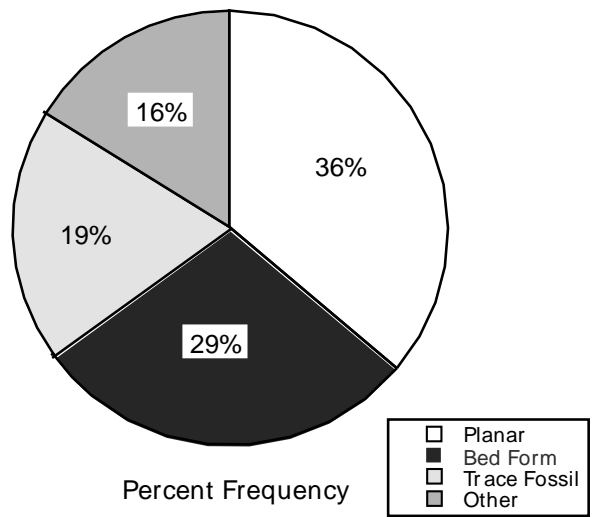

IP Category

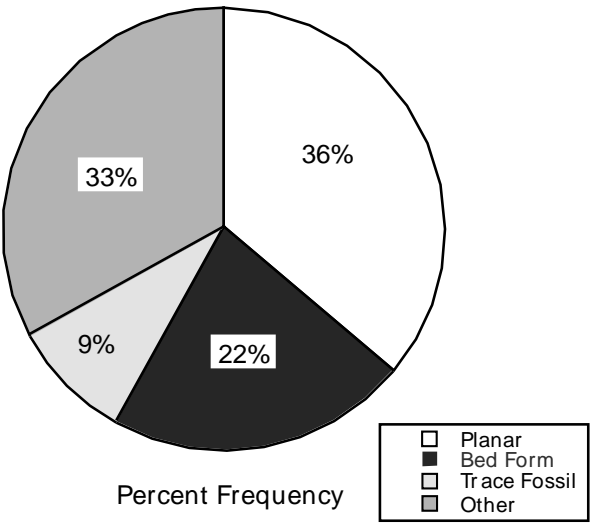

Fig. 10. Initiation points are grouped by their vertical position within the beds (IP location diagrams), and by the sedimentary feature with which they are associated (IP category). (a) Montour Falls; (b) Watkins Glen; and (c) Proximal outcrops.

present as compared to the Montour Falls outcrop. A higher percentage of IP occur in mid-bed and upper bed boundary locations (Fig. 10). The irregular bed geometries and more extensive burrowing results in an increased abundance of suitable flaws. Individual joint segments are generally shorter and IP are more closely spaced than those at the Montour Falls outcrop. Spacing of joints is similar at both outcrops. Consequently, interaction between joints within the same bed is more evident at Watkins Glen where many joints show curving terminations. Most IP are associated with planar bed boundaries, suggesting the relative importance of interaction between nearby joints in initiating fracture during the development of composite joints and the Watkins Glen outcrop contains very fine examples of composite joints (Fig. 10b). Initiation points associated with inclusions such as small nodules, thin shale laminae $(<5 \mathrm{~mm})$ and those coincident with trace fossils are more common in these beds as well. The small 


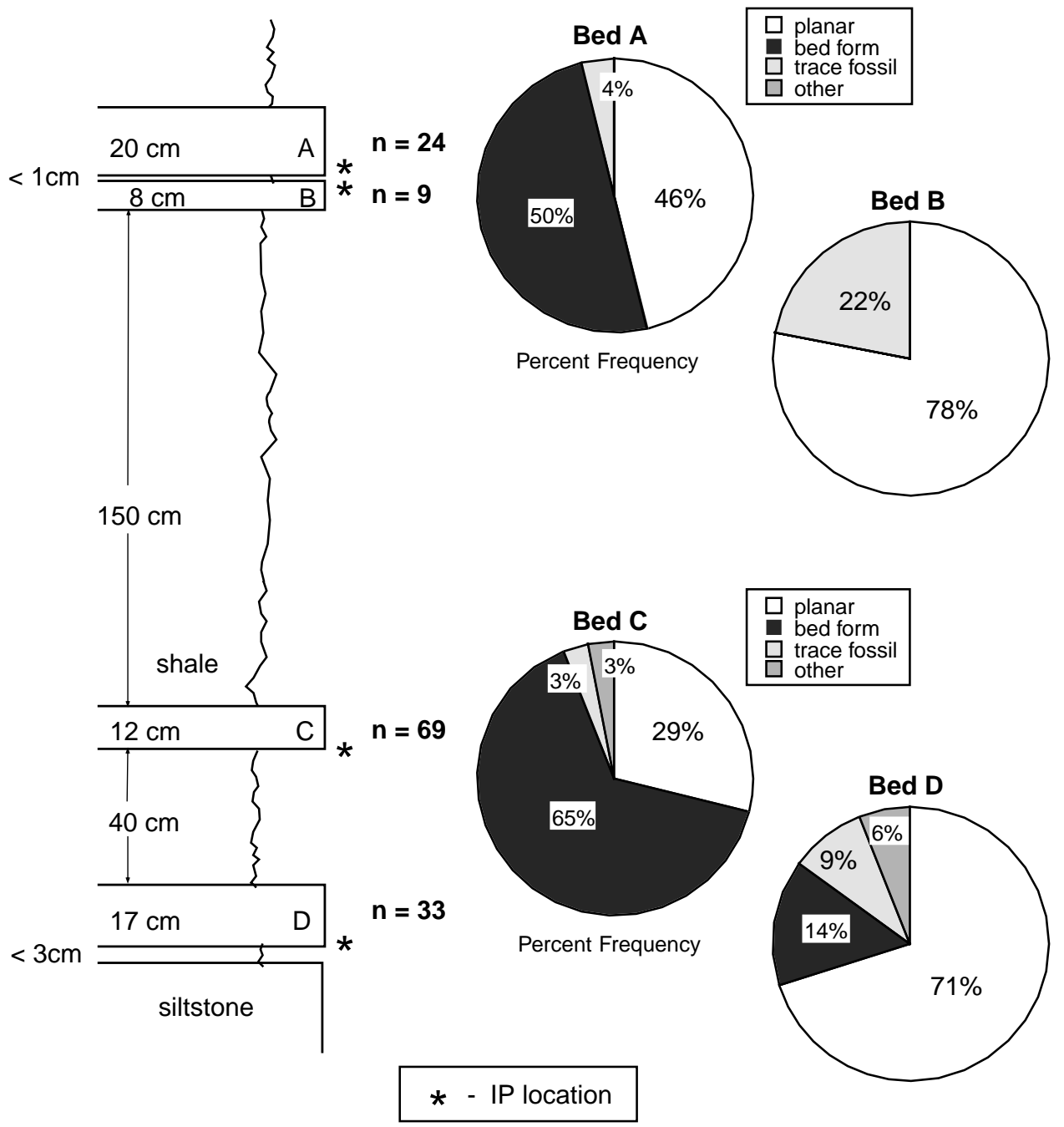

Fig. 11. Bed-by-bed comparison of IP categories at Montour Falls. The two upper pie charts compare the occurrence of IP for a pair of beds separated by a thin (1-cm) shale layer.

shale laminae are often inclusions within or near the base of beds.

\subsection{Marathon and Binghamton outcrops}

Data collected from outcrops located $60 \mathrm{~km}$ to the east of Watkins Glen and Montour Falls reflect a change in depositional environment from the deep water sheet-type turbidites of the distal portions of a basin to more proximal delta-front deposits. Siltstone beds are characterized by more lenticular and irregular bedding, and range from a few centimeters to over a meter in thickness. Hummocky bedding, storm deposits, extensive bioturbation, and soft sediment deformation all contribute to increased geometrical complexity within the siltstones. The complexity of joint interaction also increases relative to those outcrops near Watkins Glen. Joints may kink (change orientation abruptly; e.g. Fig. 8a) or develop twist hackles along their margins, typically coincident with a change in lithology (e.g. Fig. 8 b).

Initiation point location with respect to bedding is more evenly divided among bottom, middle and top positions as compared to the distal turbidites (Fig. 10c). Occurrence of initiation points at trace fossils, inclusions, and soft sediment deformation structures is greater in importance relative to the distal turbidite outcrops (Fig. 10).

One of the more striking features in these outcrops is the development of cross-fold joints in the ball-andpillow structures. Siltstone balls rest in a shale matrix with a compaction foliation. Individual siltstone balls are mechanically isolated from one another yet contain joints in the same cross-fold orientation. Here mechanical isolation is established by the lack of in plane joints in other beds or in adjacent ball-and-pillow structures. More than a meter of shale separates these balls from jointed siltstone beds. The location of IP on the perimeter of these siltstone balls is consistent with other studies of stiff 


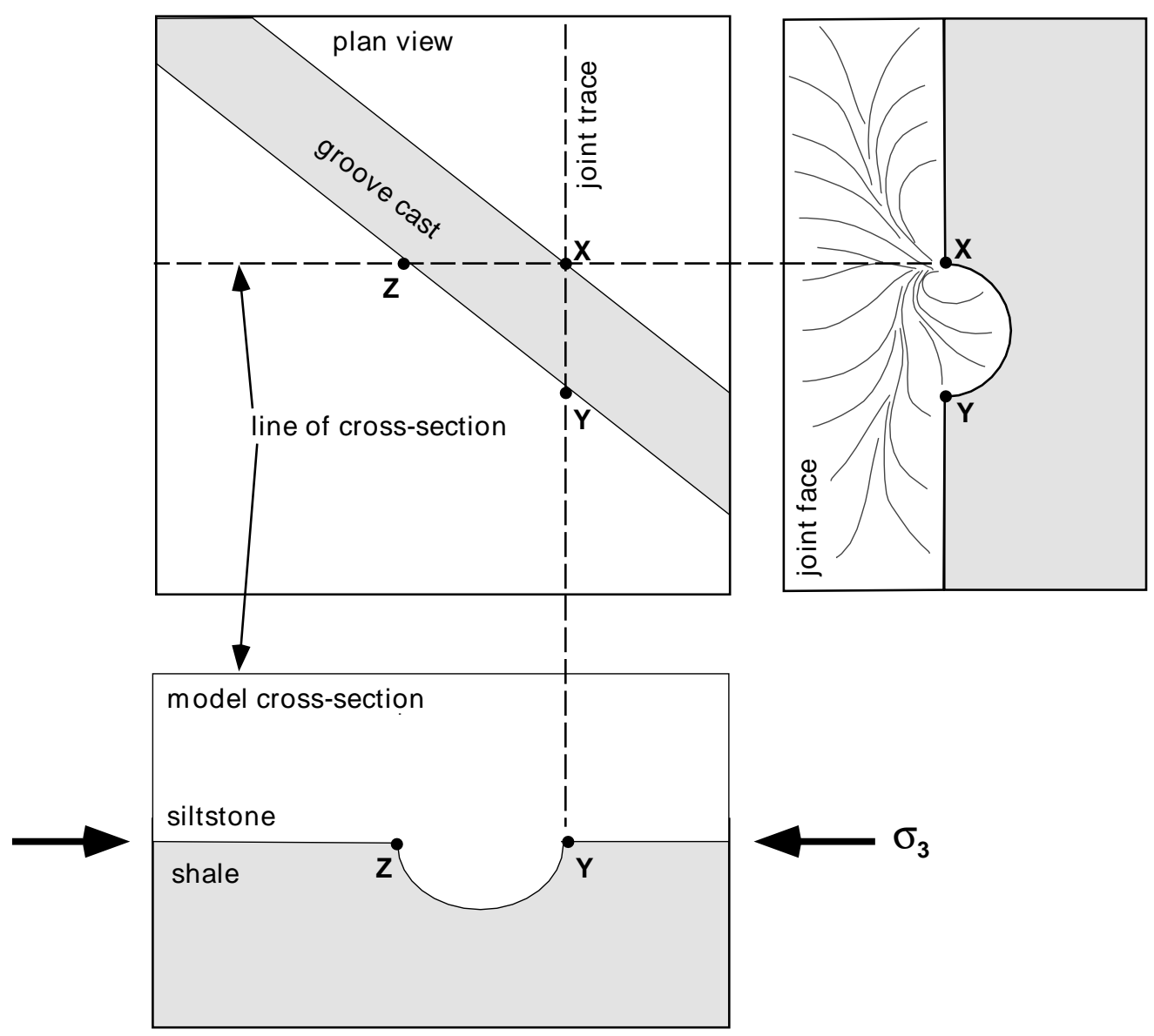

Fig. 12. Construction of a cross-section perpendicular to the plane of the joint. The aspect ratio of the bed form will change with the angle of intersection between the trend of the groove cast and the vertical plane containing $\sigma_{3}$.

inclusions in a compliant matrix (e.g., Eidelman and Reches, 1992).

At the Marathon outcrop, the shales contain a joint set $\left(075^{\circ}\right)$ that is not present in either the siltstone beds or the siltstone balls. The siltstone balls act as large, rigid inclusions in a less rigid matrix. As such, they are analogues for concretions in the black shales of the Geneseo Formation (McConaughy and Engelder, 1999). In both cases, an ENE joint set propagates in shale but does not cut through the rigid inclusion. Engelder et al. (2000) demonstrate that the ENE joint set is earlier than the cross-fold joints of the Appalachian Plateau. Concerning cross-fold joints, the difference between the behavior of the concretions in the Geneseo black shale and the siltstone balls at Marathon is that cross-fold joints propagate within the balls but not within concretions.

\subsection{Summary}

The outcrops Ithaca Formation in this study may be considered on the basis of their relative location in the Devonian Catskill Delta: distal-Montour Falls, intermediate-Watkins Glen, and proximal-Marathon and Binghamton. The distinction drawn between these three settings is based on lithological character of the outcrop rather than absolute geographic position (i.e., Fig. 1). A comparison of IP position within the bed reveals two groups of data, IP found in distal and intermediate (western) portions of the delta complex, and IP found in proximal (eastern) position. In distal turbidites (i.e., at Montour Falls), initiation occurs almost exclusively at the base of the beds where the lithologic contrast is sharp between shales and siltstones, and where basal bedforms are available to serve as local stress concentrators (Fig. 10a). This is particularly true for mechanically isolated beds (i.e., Bed C at Montour Falls). An increased abundance of IP along the top of the bed at Watkins Glen reflects the growth of composite joints where siltstone beds are more common and shale interlayers are thinner. The increased abundance of IP in mid-bed and along the top of the bed in proximal turbidites reflects the increased inhomogeneity of the beds in these portions of the basin.

Distal turbidites are characterized by a high frequency of occurrence of IP at bed boundaries and bedforms. IP occur at bedforms with about the same frequency as IP associated planar bed boundaries. A majority of those at planar boundaries appear to be related to a mechanical coupling with joints in adjacent siltstone beds leading to the development 
(a)

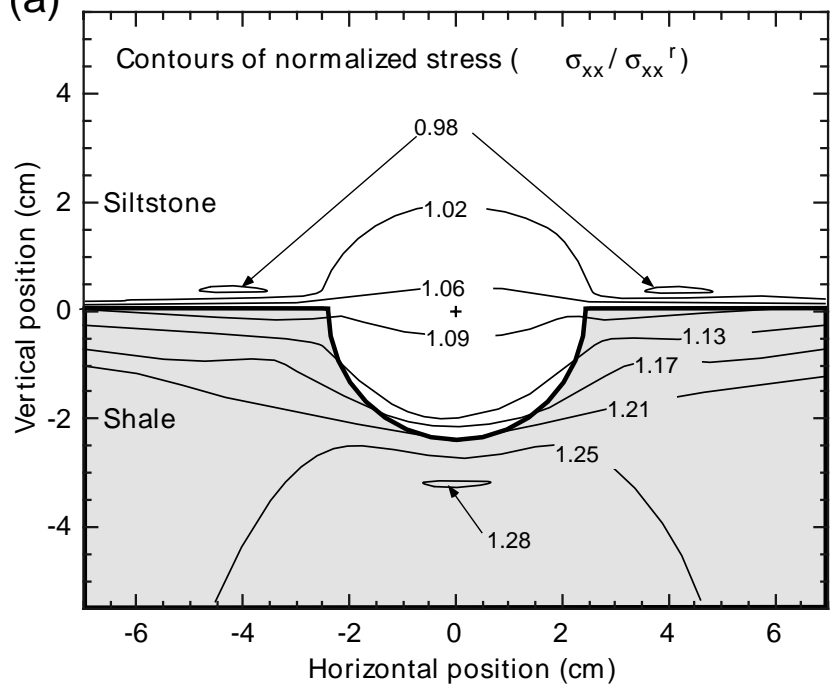

(b)

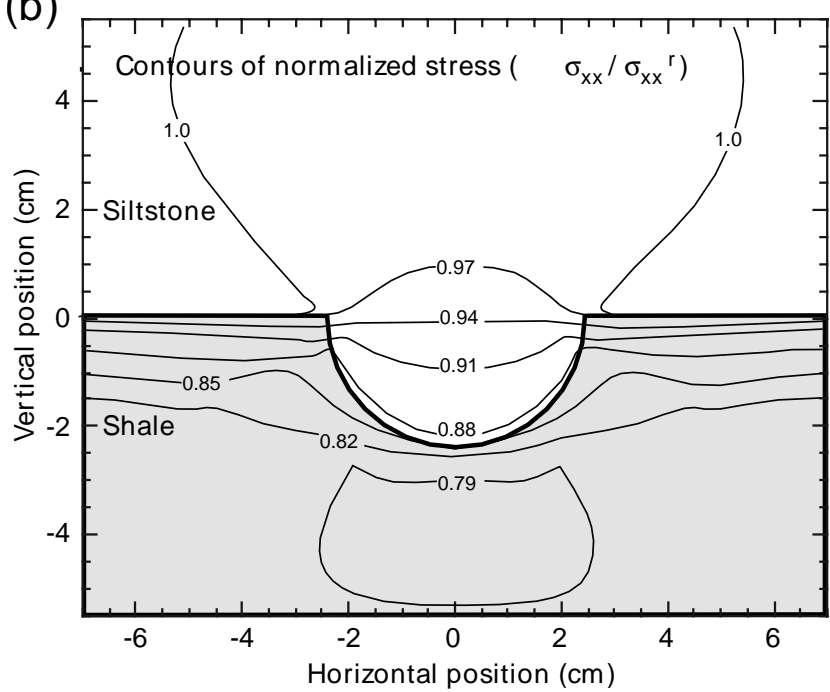

Fig. 13. (a) Contours of normalized compressive stress $\left(\sigma_{x x} / \sigma_{x x}{ }^{r}\right)$ in the vicinity of the groove cast. (b) Contours of normalized tensile stress $\left(\sigma_{x x} /\right.$ $\left.\sigma_{\mathrm{xx}}{ }^{\mathrm{r}}\right)$ in the vicinity of the groove cast.

of composite joints. In proximal turbidites the IP are more evenly divided among the four main categories, showing the increased importance of trace fossils, inclusions and soft sediment deformation structures. The relative abundance of these initiation point categories reflects the increased availability of such features, which is in turn a function of depositional environment.

\section{Primary joint initiation: stress concentration near bedforms}

One of the striking characteristics of initiation points in siltstone beds is their association with bedforms and other complex sedimentary structures. These IP are the location of primary joint initiation. The erosional base of the siltstone beds generates a sharp lithologic contrast with the underlying shale, whereas the top contact is gradational into the overlying shale. This lithologic contrast may account for the very high percentage of IP at the base of the beds. Hence, we investigate the nature of this lithological contact.

The link between bedforms and IP is particularly evident in mechanically isolated beds where other sources of stress concentration are generally unavailable (e.g., Bed C, Fig. 11). Not only are IP commonly found near bedforms, but their position with respect to the geometry of a bedform is consistent. Typically the favored location is near an abrupt intersection of the bedform with the planar bed boundary (i.e., Figs. 4 and 5). Here, localized concentration of tensile stress appears to cause joint initiation. Among the possible mechanisms for generation of stress concentrations (e.g., Pollard and Aydin, 1988), one candidate is an elastic mismatch between the convex portion of the siltstone and the concave portion of the underlying shale. Under an applied compressive load, a difference in the elastic response of the two lithologies might result in tensile stress localization near a bedform. A series of models was constructed to test the ability of an elastic and geometric mismatch such as a bedform to generate tensile stress concentrations at the IP in siltstone beds.

\subsection{Model perspective}

When examining joint surfaces in outcrop, the crosssectional view of a bed form is oriented perpendicular to the least horizontal stress, $S_{\mathrm{h}}$. While this is the plane on which the stress concentration acted, this stress concentration is generated on cross-section normal to the joint plane (Fig. 12). For two-dimensional analysis of stress concentrations around a bed form, the latter is the crosssection of interest. Many of the bed forms associated with joint initiation are elongate features with their long axis parallel to the direction of a density current. When viewed in three dimensions, they typically intersect the plane of the joint obliquely (e.g., Fig. 4). The overall height of the bed form remains the same regardless of orientation, whereas the width of the bed form changes with cross-sectional orientation.

Bedform cross-sections which present the sharpest corners to a stress concentration are those cut by joints striking less than $10^{\circ}$ from the trend of the bedform axis. When viewed along its axis, a typical groove cast might have a depth to width ratio of 0.33 . The same groove cast trending at less than $10^{\circ}$ from a joint will present a crosssectional profile with a depth to width ratio of less than 0.06 . Bedforms in these profiles are the hardest to recognize when looking at the joint because they have a relatively smooth profile in the plane of the joint. Some IP that we mapped as planar bed boundaries may actually be bedforms trending at a very low angle to the joint.

\subsection{The welded-bed model}

Our primary model has two beds $10-\mathrm{cm}$ thick and a length 


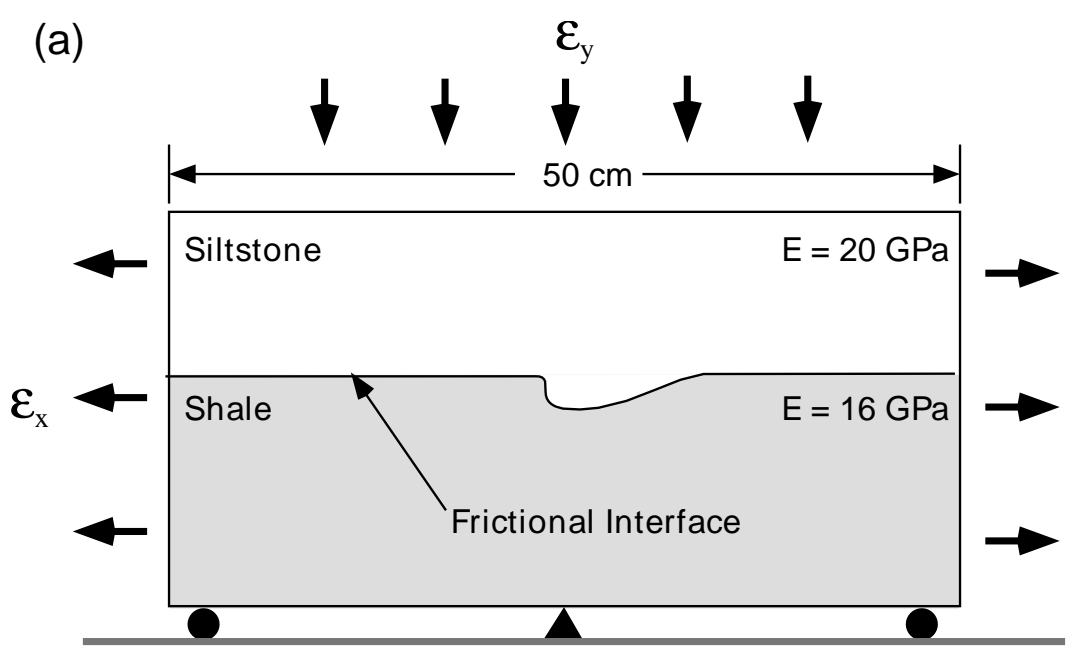

(b)

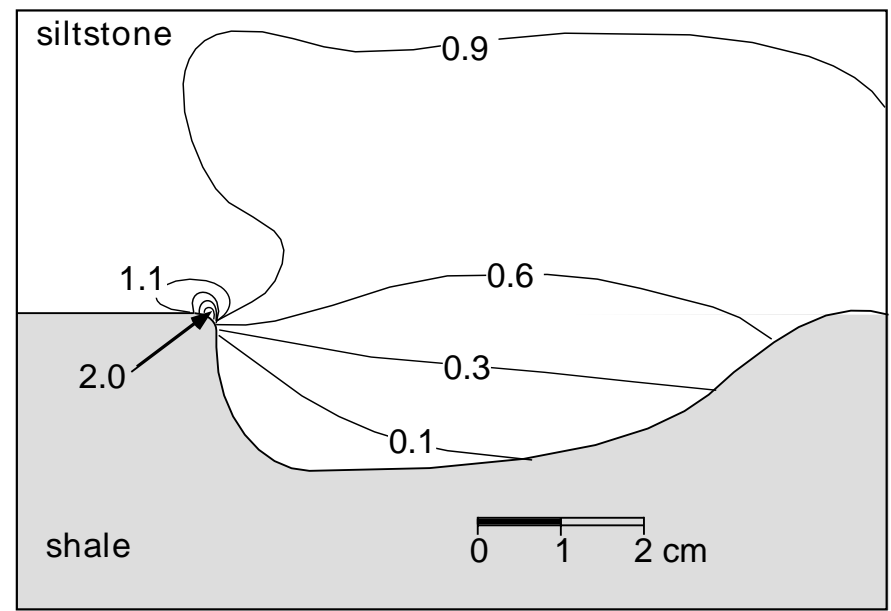

(c)

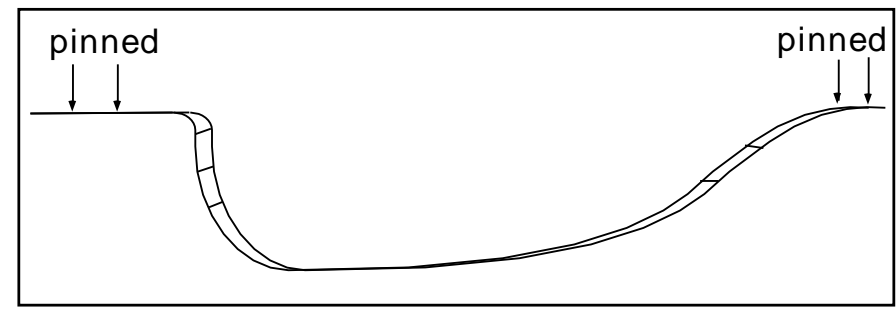

Fig. 14. Results of a model containing a frictional interface separating the two material domains, subjected to horizontal extensional strain and vertical contractional strain. (a) Relative nodal displacements along the material boundaries. The two layers are essentially pinned to one another along the horizontal bed boundary due to the vertical load normal to the interface. (b) Contours of normalized horizontal tensile stress $\left(\sigma_{\mathrm{xx}} / \sigma_{\mathrm{xx}}{ }^{\mathrm{r}}\right)$ in the siltstone. The stress concentration is highly localized at the left edge of the groove cast. Note: Determination of the magnitude of the concentration would require loading conditions more appropriate for simulating fluid-driven jointing. (c) Relative displacement of the bedform boundaries.

of $50 \mathrm{~cm}$. As a first approximation, a groove cast is modeled as a semicircular protrusion on the base of the upper bed with a radius of $2.5 \mathrm{~cm}$. Both layers are modeled as homogeneous, isotropic, elastic materials whose properties were specified by Young's modulus $(E)$ and Poisson's ratio $(\nu)$. The two layers are assumed to be perfectly bonded (e.g., no bedding slip allowed). The model assumes plane strain conditions apply, and that $S_{\mathrm{H}}$ and $S_{\mathrm{h}}$ are both horizontal. The model is fixed in the y-direction along the base of the model and an applied strain is imposed in the $\mathrm{x}$-direction to produce the desired stress field. The finite element program FRANC (Wawrzynek and Ingraffea, 1987) is used to generate a deformed mesh and calculate the resulting stresses at each node.

In the compressive environment in which these joints formed, the driving stress required for joint formation is generated by fluid pressure (Secor, 1965). The model assumes the rock to be porous and subject to uniform pore pressure. By applying contractional strain to the model and inducing compressive stress, an environment is created 
where regions of reduced compressive stress will be favored sites for joint initiation when effective stress is tensile $\left(P_{\mathrm{p}}>\right.$ $S_{\mathrm{h}}$ ). In the interbedded turbidite sequences examined in this study, joints are generally confined to individual siltstone beds. One mechanism for containing joints within the siltstones is higher compressive stresses (and therefore reduced crack-driving stress) in the shales. This was accomplished in the model by choosing a lower value of Young's modulus of the siltstones $(16 \mathrm{GPa})$ than the shales $(20 \mathrm{GPa})$. Alternatively, joints may be confined to rocks that are less resistant to fracture. If the fracture toughness $\left(K_{I c}\right)$ of the siltstones is assumed to be lower than that of the shales, joints in the siltstone would initiate at a level of effective tensile stress below the critical value for the shale. To simulate this condition the elastic modulus of the two lithologies was reversed.

An applied contractional strain of $4 \times 10-4$ results in a compressive remote stress of 6.6 $\mathrm{MPa}$ in the siltstone and 8.2 $\mathrm{MPa}$ in the shale. Resulting nodal stress values are normalized by the remote stress in the siltstone and contoured in Fig. 13a. Compressive stress is elevated within the groove cast itself, reaching a maximum of 1.2 times the remote stress at its base. Only in two small regions along the bed boundary was the compressive stress reduced, and there just by $2 \%$. If the values of Young's modulus are reversed for the two beds, simulating a stiffer siltstone over a more compliant shale, the result is a slightly different distribution of stress, but no stress reduction near the bed form. If the applied strain is extensional, such that the model is subject to tensile stress, the resulting stress distribution shows the groove cast to be less favorable for joint initiation than elsewhere in the bed (Fig. 13b). These models all use a Young's modulus ratio $\left(E_{\text {siltstone }} / E_{\text {shale }}\right)$ of 1.25 , a relatively strong contrast (Fischer, 1994). A smaller ratio further reduces the magnitude of the stress concentrations. Changes in Poisson's ratio for the two lithologies also proved ineffective in generating stress concentrations near the bed form.

These model results show that simple elastic mismatch between the beds do not generate stress concentrations in the locations indicated by field observations. Thus, the bedform was an unlikely site for joint initiation in this model domain.

\subsection{The frictional-slip model}

Given the above results an alternative set of conditions must be responsible for the stress concentration implied by the locations of initiation points. One possible explanation involves the strength of the interface between the beds. If the beds were not bonded, but instead bound along a frictional interface by loading normal to the surface, the development of high fluid pressure might contribute to stress concentrations. Fluid pressure $\left(P_{\mathrm{p}}\right)$ in the horizontal bedding interface would act against the weight of the overburden $\left(S_{\mathrm{v}}\right)$. A low effective normal load on the bedding surface gives the interface a lower frictional strength, and increases the possibility of bedding-parallel slip. On some portions of the bedding interface around a bedform, the bedding interface may be vertical. In those locations depending on orientation, $P_{\mathrm{p}}$ acts against the least principal stress, $S_{\mathrm{h}}$, rather than $S_{\mathrm{v}}$. In an over-pressured basin $P_{\mathrm{p}}$ may exceed $S_{\mathrm{h}}$ (e.g., Engelder and Fischer, 1994), resulting in effective tension, and dilating the vertical portion of the interface. The dilated interface could serve as a macroscopic flaw, subject to effective tension, with an associated tensile stress concentration at each end. This process creates a crack where none existed before.

Testing this hypothesis proved difficult because it required a model in which internal pore pressure could be prescribed for the interface, a feature not written into FRANC. However, FRANC does permit the definition of frictional interfaces between materials. This capability was used for a model in which applied tension served as a proxy for effective tensile stress. To model conditions suitable for the development of vertical fluid-driven joints we require that $S_{\mathrm{v}}>P_{\mathrm{p}}>S_{\mathrm{h}}$. This results in effective tension acting normal to vertical surfaces such as joints and dilated vertical bedding interfaces. These conditions were simulated by applying vertical contractional strain $\left(\varepsilon_{\mathrm{yy}}\right)$, and a horizontal extensional strain $\left(\varepsilon_{\mathrm{xx}}\right)$. The model geometry was similar to that previously used to model a groove cast on a perfectly bonded interface (Fig. 14a).

Fig. 14c shows the deformed model displacements along the interface in the vicinity of the groove cast. It demonstrates the increased separation of vertical bedding surfaces due to effective tension. A contour plot of normalized tensile stress $\left(\sigma_{\mathrm{xx}} / \sigma_{\mathrm{xx}}{ }^{\mathrm{r}}\right)$ reveals a localized stress concentration at the junction of the bedform with the planar bed boundary (Fig. 14b). Under these conditions the absolute magnitude of the stress concentration is less meaningful because the stress field that results is not representative of a compressive environment, a model that is not possible with the current tools available through FRANC. However, the relative location of the stress concentration is of interest. The results suggest that a stress concentration is likely to occur in a location consistent with field observations given a frictional interface between the siltstone and shale beds and fluid pressure in excess of the least principal stress, which is bed parallel.

\section{Secondary joint initiation: stress concentrations near existing joints}

The growth of a composite joint at Montour Falls (i.e., Beds A and B), demonstrates several important characteristics of stress concentration that merit further consideration (Fig. 3 Fig. 9). First, secondary joint initiation at stress concentrations near existing joints is subordinate to primary initiation at complex sedimentary structures. We know this because joint initiation at bedforms is favored when siltstone beds are mechanically isolated within thick shale beds and joint initiation during growth of composite jointing 


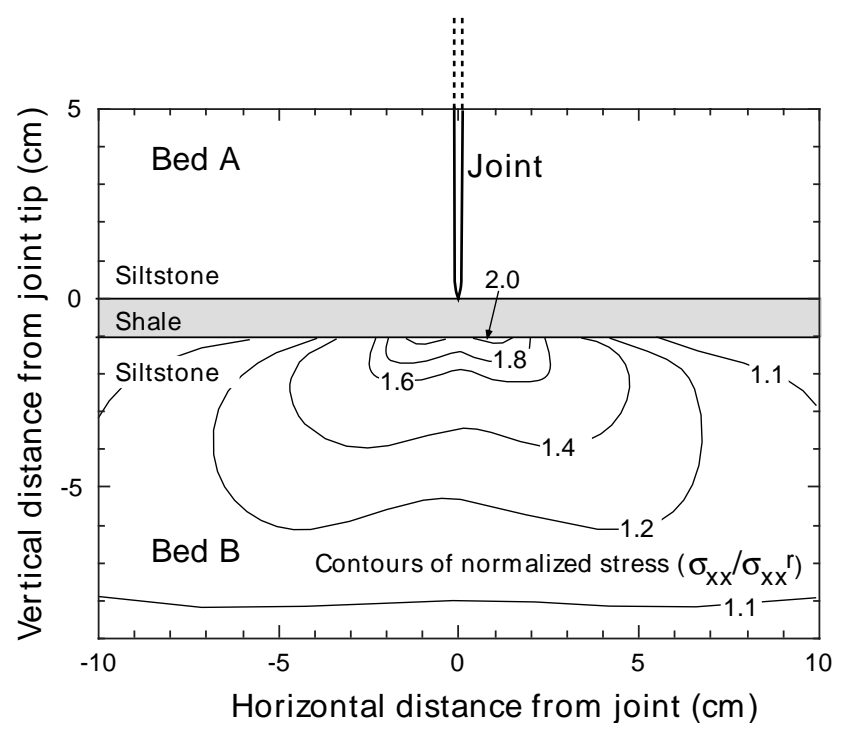

Fig. 15. Contour plot of normalized horizontal stress $\left(\sigma_{x x} / \sigma_{x x}{ }^{r}\right)$ in the lower siltstone bed in the vicinity of a pressurized joint. Joint height is $20 \mathrm{~cm}$. A maximum stress concentration in excess of twice the remote stress is achieved in two small regions on either side of the joint.

starts at bed forms. Second, $1 \mathrm{~cm}$ of shale can stop joint propagation between siltstone beds. Although transmission of a stress concentration across the shale layer still takes place, $1 \mathrm{~cm}$ is treated as a threshold above which growth of composite joints is limited. Third, a joint driven through the shale interface may have a limited propagation dimension. For example, a joint driven from the thicker siltstone Bed A (i.e., a taller joint) crosses completely through the thin Bed B. However, a joint driven from the thinner Bed B (i.e., a shorter joint) crosses into Bed A but is not driven very far (Fig. 9). Both characteristics reflect the nature of the mechanical coupling between siltstone beds and these characteristics can be understood through further modeling.

\subsection{Model configuration}

Initiation points at planar bed boundaries are found when siltstone beds are mechanically coupled through thin shale layers and joint propagation jumps from one bed to the next to form a composite joint. Helgeson and Aydin (1991) studied the morphology of composite joints on the Appalachian Plateau and used a finite element model to investigate the influence of an existing joint, subject to remote tension, on the subsequent development of joints in an adjacent layer. They proposed that stress concentrations at the tips of existing joints are transmitted across thin shale interbeds into adjacent siltstones. This stress perturbation may be superimposed on stress concentrations at optimally located flaws in the unjointed bed, resulting in fracture of the bed. The maximum stress concentration is offset from the plane of the existing joint due to the dual-lobed geometry of the crack-tip stress field. They found the amount of offset between the individual joints to be a function of the thickness of the intervening shale. Our analysis, like that of Helgeson and Aydin, examines stress perturbations in adjacent, uncracked layers resulting from an existing joint, but specifically seeks to investigate the problem of fluid-driven jointing in a compressive environment. Important questions include: How effectively is the stress concentration generated by a pressurized joint transmitted across an intervening shale layer when the shale layer is in a compressional environment?

Our numeric modeling of fluid-driven jointing follows Fischer (1994) and Fischer et al. (1995) in using a simple static model (i.e., FRANC) that does not account for the poroelastic response of sedimentary rocks to changes in pore pressure (Fig. 15). The stress field surrounding a fluid-filled joint is approximated by subjecting the model to a horizontal contractional strain $\left(\epsilon_{\mathrm{xx}}\right)$ and prescribing an internal pore pressure that acts normal to the walls of the joint. The siltstone beds are assumed to be porous media subject to the same pore pressure prescribed for the joint. Flaws within the lower siltstone bed are subject to the same balance of forces acting on the joint in the upper siltstone bed. In this simple model, the crack-driving stress $\Delta \sigma$ acting on a flaw in the lower bed equals the sum of the pore pressure within the flaw $\left(\mathrm{P}_{\mathrm{p}}\right)$ and the local confining stress $\left(\sigma_{\mathrm{xx}}\right)$, which varies with $\mathrm{x}-\mathrm{y}$ position in the bed:

$\Delta \sigma=\left|P_{\mathrm{p}}\right|-\sigma_{\mathrm{xx}}$

For a constant pore pressure, local crack driving stress varies directly with confining stress in response to perturbations associated with the existing joint.

\subsection{Coupling through a shale interface}

To investigate the stress concentration across a shale interface, elastic constants were used similar to those chosen by Helgeson and Aydin (1991); a Poisson's ratio of 0.18 for both lithologies, and a Young's modulus $15 \%$ higher for the shale $(18.4 \mathrm{GPa})$ than for the siltstone $(16 \mathrm{GPa})$. These values were selected to simulate remote stresses $15 \%$ higher in the shale interlayer than in the adjacent siltstones. This is a reasonable stress ratio based on estimates of in-situ stress in layered rock (Evans et al., 1989). An applied strain of $1 \times 10^{-3}$ results in a theoretical crack-normal stress $\left(\sigma_{\mathrm{xx}}{ }^{\mathrm{r}}\right)$ of 16.5 $\mathrm{MPa}$ in the siltstones and 19 MPa in the shale layer. An internal pore pressure of $-24 \mathrm{MPa}$ is applied to the joint walls, yielding a crack-driving stress of $7.5 \mathrm{MPa}$ in the siltstones, a value consistent with estimates of crack-driving stress for Mode I fractures in a variety of geologic media (Segall and Pollard, 1983; Vermilye and Scholz, 1995). The layers were perfectly bonded.

The joint-tip stress concentration causes local tensile stresses that can exceed the crack-driving stress $\left(\Delta \sigma^{r}\right)$ on the initial joint. Local crack-driving stress can be normalized by dividing by the far-field driving stress $\left(\Delta \sigma / \Delta \sigma^{r}\right)$ and the resulting ratio contoured over the region of interest (Fig. 15). Larger values indicate regions where conditions are 


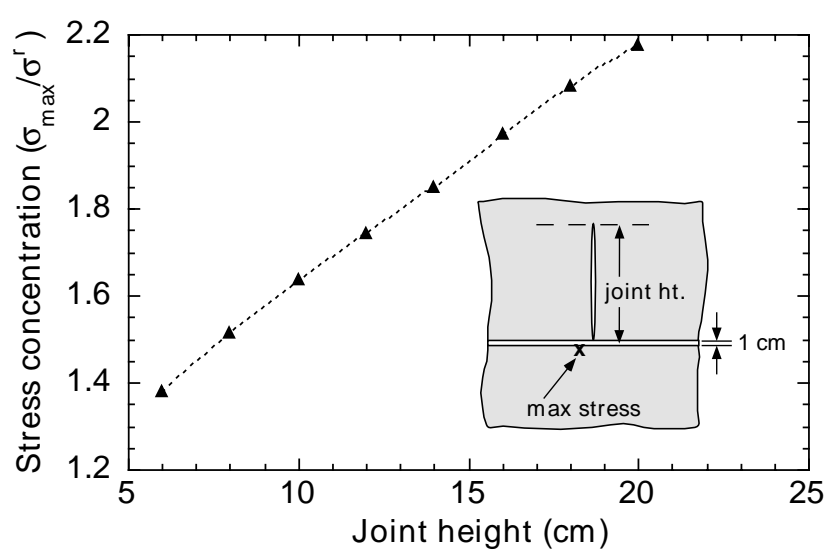

Fig. 16. Maximum stress concentration $\left(\sigma_{\max } / \sigma_{x x}{ }^{r}\right)$ plotted as a function of joint height. Maxima measured at the location marked $\mathrm{x}$ for each model. The gradual decrease in slope with increased joint height reflects the square root of $2 \mathrm{c}$ term in the expression for stress intensity.

more favorable for initiation of a new joint. Maxima occur along the upper boundary of the uncracked siltstone. The horizontal offset of the maxima from the plane of the existing joint scales with the thickness of the shale interlayer where the stress concentration is $2 \times$. The shape of the stress contours reflects the symmetrical lobate geometry associated with crack-tip stress fields. Helgeson and Aydin (1991) found the same general geometry in their extensional model and concluded that the locations of the maxima were consistent with the horizontal offset between the planes of the individual joints observed in composite joints in interbedded sequences on the Appalachian Plateau. However, within Bed B the lobate geometry of the crack-tip stress field was not strong enough to cause joint initiation without driving a joint directly through the shale bed from Bed A. In fact, the alignment of joints at the crossing point suggests that the crack tip stress was responsible for driving the joint through the shale interface from above rather than initiating a joint below the interface.

We also note that slip at bedding boundaries eliminates the crack-tip stress singularity and thus greatly reduces the stress concentration just ahead of the crack-tip (Dollar and Steif, 1989). Whether the joint crosses the interface, re-initiates on the other side, or simply arrests, depends on the coefficient of friction of the interface and the ratio of normal stress to shear stress at the interface (Renshaw and Pollard, 1995).

Joints in the two beds are typically offset by about $1 \mathrm{~cm}$, an amount predicted by the model for an interlayer thickness of $1 \mathrm{~cm}$. The plume axis, which marks the region of maximum crack-driving stress, is commonly shifted in one of the two beds towards the other bed (Fig. 9). This behavior is consistent with the presence of a stress concentration along the bed boundary (due to an existing joint in the other bed) during propagation of a joint in the uncracked bed. The stress concentration is not large enough to initiate joint propagation in the unjointed bed but it is sufficient to guide the rupture driven from some other point within the bed. Where it was possible to make a determination, joints appear to have initiated in Bed A first, followed by initiation in Bed B. Bed A contains a population of bedforms, whereas Bed B does not. Joints in Bed A may have been required to initiate jointing in Bed B since bedforms were unavailable to serve as stress risers.

\subsection{Effect of joint height on coupling through a shale interface}

Joint propagation across a shale interface from Bed A appears to be more effective than propagation from the shorter Bed B. This conclusion is based on the length of the rupture down into Bed B versus the length of rupture up into Bed $\mathrm{A}$. The extent of the rupture appears to be related to the height of the parent joint (i.e., the host bed).

To investigate the effect of joint height (i.e., the thickness of the upper siltstone bed) on crack-driving stress in the uncracked bed, elastic constants were used as specified above. A series of models show the influence of joint height on the magnitude of the stress concentration. Because cracktip stress intensity varies with crack length, an increase in joint height should result in an increase in local driving stress. Joint height was increased in $2 \mathrm{~cm}$ increments from 6 to $20 \mathrm{~cm}$, the commonly observed range of bed thicknesses in the Montour Falls and Watkins Glen outcrops. In each model the lower joint tip was located in the interface. All other model parameters remained unchanged. Maximum values of stress are again converted to normalized driving stress and plotted as a function of joint height (Fig. 16). Over the range of heights modeled, the relationship is approximately linear, increasing from 1.35 to 2.15 times the remote driving stress. The lateral position of the maxima with respect to the joint did not change with changes in joint height, as was shown by Helgeson and Aydin (1991). The jump from Bed A to Bed B does not require contact as long as the shale interface is less than $1 \mathrm{~cm}$ thick. However, the jump from Bed B back to Bed A requires contact between the beds. The distance of joint propagation after jumping beds and the thickness of the shale interlayer at the crossing point both are consistent with fact that short joints in thinner beds have a small crack-tip stress intensity.

\section{Conclusions}

Initiation points (IP) are associated with into two types of structures that concentrate stress in siltstone beds: primary sedimentary structures and pre-existing joints. The relative importance of each type of structure varies with stratigraphic position of the jointed body. Bodies that are mechanically isolated from other jointed bodies, such as individual beds surrounded by thicker shales, have a higher percentage of their IP associated with sedimentary features 
such as bedforms. These are the locations of primary joint initiation. Joints in beds that are in mechanical communication appear to initiate at planar bed boundaries mostly through interaction with pre-existing joints. These are the locations of secondary joint initiation.

Three categories of sedimentary structures that concentrate stress necessary for primary joint initiation include: bedforms; trace fossils; and other IP including inclusions and soft-sediment deformation structures. Initiation at irregular boundaries, such as bedforms or ball-and-pillow structures, commonly occurred at a region of sharp curvature on the boundary. A sharp transition from a horizontal bed boundary to a vertical surface on a bedform is the favored spot for an initiation point. In instances in which a linear bedform intersects the plane of a joint at an angle (i.e., non-orthogonal) the local fracture surface at the IP is typically misaligned with the overall orientation of the joint. This indicates a strong geometric component to the mechanism responsible for the stress concentration.

Field evidence supports the hypothesis that sedimentary features such as bedforms serve to concentrate stress, thus becoming preferred sites for joint initiation. A mechanism for generating a stress concentration is an elastic mismatch between a siltstone bed containing a convex bedform and an underlying shale bed. When the two beds are assumed to be perfectly bonded, finite element modeling of the stress field near a groove cast produced no significant stress concentrations. Models using a frictional interface between the two beds generate stress concentrations near vertically oriented bedding surfaces, locations that field evidence shows are associated with joint initiation. Pore fluids at pressures in excess of the least principal stress, acting against nonhorizontal surfaces of a bedform, may provide the additional drive for joint initiation. In mechanically coupled siltstone beds, a modest joint-tip stress concentration across a shale layer (e.g., $<3 \times$ for a $1 \mathrm{~cm}$ thick bed) permits a competition between sedimentary structures and pre-existing joint tips to initiate new jointing.

\section{Acknowledgements}

We dedicate this paper in the memory of Paul Hancock who took a great interest in our work on jointing in the Devonian section of the Appalachian Plateau. Our work was supported by Penn State's Seal Evaluation Consortium (SEC). An early version of this paper was reviewed by Don Fisher and Peter Flemings. Bill Dunne, Byron Kulander, and Peter Lemiszki contributed valuable time and effort during the JSG review process.

\section{References}

Bahat, D., Engelder, T., 1984. Surface morphology on cross-fold joints of the Appalachian Plateau, New York and Pennsylvania. Tectonophysics 104, 299-313.
Bankwitz, P., 1965. Uber klufte; I. Beobachtungen im Thuringischen Schiefergebirge. Geologie 14, 241-253.

Dollar, A., Steif, P.S., 1989. A tension crack impinging upon frictional interfaces. Journal of Applied Mechanics 56, 291-298.

Eidelman, A., Reches, Z., 1992. Fractured pebbles-A new stress indicator. Geology 20, 307-310.

Engelder, T., 1979. The natural deformation within the outer limits of the central Appalachian foreland fold and thrust belt in New York State. Tectonophysics 55, 289-310.

Engelder, T., Fischer, M.P., 1994. Influence of poroelastic behavior on the magnitude of minimum horizontal stress, $\mathrm{S}_{\mathrm{h}}$, in overpressured parts of sedimentary basins. Geology 22, 949-952.

Engelder, T., Geiser, P., 1980. On the use of regional joint sets as trajectories of paleostress fields during the development of the Appalachian Plateau, New York. Journal of Geophysical Research 85, 6319-6341.

Engelder, T., Haith, B.F., Younes, A., 2000. Horizontal slip along Alleghanian joints of the Appalachian plateau: Evidence that joints persist during later penetrative strain, Tectonophysics (in press).

Evans, K., Engelder, T., Plumb, R.A., 1989. Appalachian Stress Study 1: A detailed description of in situ stress variations in Devonian Shales of the Appalachian Plateau. Journal of Geophysical Research 94, 1729-1754.

Evans, M.A., 1994. Joints and decollement zones in the Middle Devonian Shales: Evidence for multiple deformation events in the central Appalachians. Geological Society of America Bulletin 106, 447-460.

Fischer, M.P., 1994. Application of linear elastic fracture mechanics to some problems of fracture propagation in rock and ice. Ph.D. dissertation. Pennsylvania State University, University Park, Pennsylvania, p. 232.

Fischer, M.P., Gross, M.R., Engelder, T., Greenfield, R.J., 1995. Finiteelement analysis of the stress distribution around a pressurized crack in a layered medium: implications for the spacing of fluid-driven joints in bedded sedimentary rock. Tectonophysics $247,49-64$.

Helgeson, D.E., Aydin, A., 1991. Characteristics of joint propagation across layer interfaces in sedimentary rocks. Journal of Structural Geology 13, 897-911.

Hodgson, R.A., 1961. Classification of structures on joint surfaces. American Journal of Science 259, 493-502.

Kirchgasser, W.T., House, M.R., 1981. Upper Devonian goniatite biostratigraphy. In: Oliver, W.A., Klapper, G. (Eds.), Devonian biostratigraphy of New York; Part 1, Text. International Union of Geological Sciences. Subcommission of Devonian Stratigraphy, Washington, D.C., pp. 39-46.

Kulander, B.R., Dean, S.L., 1985. Hackle plume geometry and joint propagation dynamics. In: Stephannson, O. (Ed.), Fundamentals of rock joints: International Symposium on Fundamentals of Rock Joints, Bjorkliden, Sweden, Proceedings, pp. 85-94.

Kulander, B.R., Barton, C.C., Dean, S.L., 1979. Application of fractography to core and outcrop fracture investigations. Washington, D.C., U.S. Government Printing Office, U.S. Department of Energy, Paper METC/SP-79/3, 174 pp.

Lundegard, P.D., Samuels, N.D., Pryor, W.A., 1985. Upper Devonian turbidite sequence, central and southern Appalachian Basin: Contrasts with submarine fan deposits. Geological Society of America Special Paper 201, 107-121.

McConaughy, D.T., Engelder, T., 1999. Joint interaction with embedded concretions: Joint loading configurations inferred from propagation paths. Journal of Structural Geology 21, 1049-1055.

Nickelsen, R.P., Hough, V.D., 1967. Jointing in the Appalachian Plateau of Pennsylvania. Geological Society of America Bulletin 78, 609-630.

Pollard, D.D., Aydin, A., 1988. Progress in understanding jointing over the past century. Geological Society of America Bulletin 100, 1181-1204.

Renshaw, C.E., Pollard, D.D., 1995. An experimentally verified criterion for propagation across unbounded frictional interfaces in brittle, linear elastic materials. International Journal of Rock Mechanics Min. Sci. \& Geomech. Abstr. 32, 237-249.

Secor, D.T., 1965. Role of fluid pressure in jointing. American Journal of Science 263, 633-646. 
Segall, P., Pollard, D.D., 1983. Joint formation in granitic rock of the Sierra Nevada. Geological Society of America Bulletin 94, 563-575.

Vermilye, J.M., Scholz, C.H., 1995. Relation between vein length and aperture. Journal of Structural Geology 17, 423-434.

Wawrzynek, P.A., Ingraffea, A.R., 1987. Interactive finite element analysis of fracture processes: An integrated approach. Theoretical and Applied Fracture Mechanics 8, 137-150.
Younes, A.I., Engelder, T., 1999. Fringe cracks: Key structures for the interpretation of progressive Alleghanian deformation of the Appalachian Plateau. Geological Society of America Bulletin 111, 219-239.

Zhao, M., Jacobi, R.D., 1997. Formation of regional cross-fold joints in the northern Appalachian Plateau. Journal of Structural Geology 19, 817834. 